\title{
Toxicology
}

\section{The Toxicity of Inhaled Methanol Vapors}

Robert Kavet, Sc.D. and Kathleen M. Nauss, Ph.D.

\section{ABSTRACT}

Methanol could become a major automotive fuel in the U.S., and its use may result in increased exposure of the public to methanol vapor. Nearly all of the available information on methanol toxicity in humans relates to the consequences of acute, rather than chronic, exposures. Acute methanol toxicity evolves in a well-understood pattern and consists of an uncompensated metabolic acidosis with superimposed toxicity to the visual system. The toxic properties of methanol are rooted in the factors that govern both the conversion of methanol to formic acid and the subsequent metabolism of formate to carbon dioxide in the folate pathway. In short, the toxic syndrome sets in if formate generation continues at a rate that exceeds its rate of metabolism. Current evidence indicates that formate accumulation will not challenge the metabolic capacity of the folate pathway at the anticipated levels of exposure to automotive methanol vapor.

Key Words: methanol, toxicity, folate, formate, auto emissions.

\section{INTRODUCTION}

\section{A. Background}

Methanol has the potential to become a major automotive fuel in the U.S. in the next century. One attractive feature linked to the use of methanol is that emissions from methanolfueled vehicles are expected to result in ambient concentrations of criteria pollutants that are no greater than and, quite likely, lower than those that result from gasoline or diesel emissions.

The Clear Air Act requires that it be established that implementing such a technology on a mass basis will not degrade environmental quality or compromise public health. Although substituting methanol for currently used fuels is expected to reduce ambient concentrations of criteria pollutants such as particular matter, oxides of nitrogen, and ozone, ${ }^{1,2}$ its use may increase airbome concentrations of two gaseous pollutants of potential concern: formaldehyde and methanol..$^{3,4}$ Methanol emissions arise from its release as uncombusted material in the exhaust and also from its evaporation during refueling and following ignition turn-off; evaporative emissions also occur during the daily heating of the fuel tank. Formaldehyde is a byproduct resulting from the incomplete combustion of methanol.

The Environmental Protection Agency (EPA) has identified the importance of technically evaluating the relevant health issues associated with these two pollutants. At the request of the EPA, the Health Effects Institute (HEI) conducted an analysis for its sponsors and the public of what emissions-related health problems, if any, would emerge if methanol were to become more widely used as an automotive fuel. This analysis was published as a special report of the HEl Health Research Comnittee in 1987.5

The report focused on the potential health effects of exposure of the general public to methanol vapor that might result from an introduction of methanol-powered motor vehicles in the general fleet. The report also evaluated, insofar as available knowledge permitted, the likely alth implications of such exposure. The report excluded analysis of the effects of accidental spills, ingestion, and worker expsire

The objectives of the repore to (1) review the nature and mechanisms of methanol toxlcity (B) evaluate whether or not the known effects of methanol expected at anticipated levels of exposure, and (3) identify yresate in which critical knowledge is lacking and the research that forfild supply the needed information. Although issues such as spillage, oral ingestion of liquid methanol, and occupational exposures to methanol vapors were not targeted specifically, the analyses presented may, nonetheless, be applicable to these situations as well.

Since the report was published, there has been increased interest in the potential use of methanol as a principal automotive fuel in the U.S. At the state and national levels, strategies for implementing methanol fuels are currently under consideration. The following is a condensed and edited version of the HEI Report on Automotive Methanol Vapor and Human Health. It has been updated where appropriate to incorporate new information on the projected ambient concentrations of methanol under varjous exposure scenarios. We are publishing it in this form because we believe that a summary of the current state of knowledge about the effects of methanol and the likely impact of exposure to its vapors will be of considerable interest to toxicologists and other scientists as policies relating to methanol fuel are developed.

\section{B. Organization of the Review}

A comprehensive assessment of the potential health impacts of exposure to methanol vapor and an identification of further issues require integration of information from a variety of sources. Therefore, the next three sections of this paper present topics and issues that constitute the building blocks of an environmental health risk assessment of methanol. The final section organizes and synthesizes the technical material in an analytical framework, and provide conclusions and recommendations. A brief description of each section follows:

Robert Kavet, Sc.D. (corresponding author), Environmental Research Information, Inc., 451 Sherman Avenue, Palo Alto, CA 94306; and Kathleen M. Nauss, Ph.D., Health Effects Institute, 141 Portland Street, Cambridge, MA 02139. 
Section 11 - Fuel Properties and Anticipated Ambient Concentrations of Methanol: this section reviews the characteristics of nethanol that recommend it as a vehicle fucl and summarizes studies conducted by the EPA that project the ambient concentrations of methanol that will result from its use as a motor vehicle fuel. These projections cover various exposure scenarios (e.g., expressway, personal garage) and are critical to help assess whether or not people are likely to experience health effects under anticipated exposure conditions.

Section IIl - Toxicity of Methanol: this section discusses the signs and symptoms of methanol toxicity, a subject of numerous publications in the toxicologic and clinical literature since the turn of the century. This literature is almost exclusively concerned with the acute effects of methanol poisoning following brief intakes of large quantities of methanol and supplies, very little information about chronic, low-level exposure. The section highlights the differences between primate and non-primate species in terms of their sensitivity to acute methanol toxicity. Such distinctions are important for subsequent discussions of the metabolism of methanol and its toxic mechanisms in humans. The section also reviews the literature that deals with long-term or repeated human exposures to methanol and discusses the limited literature on chronic exposures of animals to methanol.

Section IV - Metabolism of Methanol and Its Mechanisms of Toxicity: the uptake, distribution, and subsequent fate of methanol and its metabolites are described. The discussion includes the biochemical basis for the interspecies differences in susceptibility presented in Section III. This material provides the underpinnings for dose-response relationships whose understanding is vital to the overall purposes of this report.

Section V - Conclusion: here, the information from the preceding four sections is synthesized to project the extent to which known toxic processes may occur under predicted ambient exposure conditions. The analysis considers inhalation as the principal route of exposure as well as the metabolic and excretory pathways described in Section IV. Finally, the section identifies areas in which the health data base might be improved and advances recommendations for research that can help in further reducing uncertainties in estimating the health effects of protracted or repeated lowlevel exposures to methanol.

\section{FUEL PROPERTIES AND ANTICIPATED AMBIENT CONCENTRATIONS OF METHANOL}

\section{A. Methanol as a Fuel}

Methanol $\left(\mathrm{CH}_{3} \mathrm{OH}\right)$, also called methyl alcohol, is the simplest of all the alcohols. In its pure form, it is a clear, colorless liquid at room temperature and has the physical and chemical characteristics listed in Table 1. Additional characteristics of methanol relate to its use as a motor vehicle fucl. Pure methanol ty has an octane rating of between 106 and 115 and an energy content of about $16 \mathrm{~kJ} / \mathrm{cm}^{3}$; in-use gasoline fuels have octane: ratings ranging from 87 to 94 and an energy content roughly twice that of methanol. 2.7

From its discovery in the early 19 th century up to the mid. 1920s, methanol was made exclusively from the destructive. distillation of wood, which led to its well-known name, wood: alcohol, a term that persists to the present. Methanol found a variety of personal, commercial, and industrial uses as a solvent, medicinal agent, and as a source of energy. In the last century, for example, methanol was used in France for lighting, heating, and cooking. Facing gasoline shortages in the 1930s, several European countries equipped civilian and military vehicles with wood-burning units that provided power in the form of alcohol vapors. ${ }^{8}$ For the past 6 decades, however, most methanol has been made by reacting carbon monoxide $(\mathrm{CO})$ with hydrogen $\left(\mathrm{H}_{2}\right)$ at elevated temperature and pressure, and methanol continues to be used in a wide variety of commercial and industrial applications (e.g., manufacture of formaldehyde, antifreeze ingredient, denaturant).$^{7.8}$

The economic, political, and social factors connected with the future of methanol in the automotive fuel marketplace fall outside of the scope of this report. Suffice to say that methanol combines several important attributes that highlight its potential ${ }^{3}$ for mass use, which, in turn, justifies an evaluation of its

\section{Table 1}

\section{Physical and Chemical Properties of Methanol}

$\begin{array}{ll}\text { Physical state } & \text { Colorless, volatile liquid } \\ \text { Molecular formula } & \mathrm{CH}_{3} \mathrm{OH} \\ \text { Molecular weight } & 32.04 \\ \text { Boiling point } & 64.7^{\circ} \mathrm{C} \\ \text { Melting point } & -97.8^{\circ} \mathrm{C} \\ \text { Specific gravity } & 0.7915\left(@ 4^{\circ} \mathrm{C}\right) \\ \text { Vapor pressure } & 160 \mathrm{mmHg}\left(@ 30^{\circ} \mathrm{C}\right) \\ \text { Refractive index } & 1.3292\left(@ 20^{\circ} \mathrm{C}\right) \\ \text { Flammability } & \\ \quad \text { Flash point } & 12^{\circ} \mathrm{C} \\ \quad \text { Explosive limits } & 6.0 \text { to } 36.5 \% \text { volume in air } \\ \text { Ignition temperature } & 470^{\circ} \mathrm{C} \\ \text { Percent in saturated air } & 21.05\left(@ 30^{\circ} \mathrm{C}\right) \\ \text { Density of saturated air } & 1.02 \\ \text { (air = I) } & \text { Miscible with water, alcohols, ketones, } \\ \text { Solubility } & \text { esters, halogenated hydrocarbons, and } \\ & \text { benzenc } \\ \text { I mg/ml }<> & 764 \mathrm{ppm} \text { at } 25^{\circ} \mathrm{C}, 760 \mathrm{mmHg} \\ \text { I ppm }<> & 1.31 \mathrm{mg} / \mathrm{m}^{3} \text { at } 25^{\circ} \mathrm{C}, 760 \mathrm{mmHg}\end{array}$

From Rowe, V. K. and McCollister, S. B., Alcohols, in Patty's Industria. Hygiene and Toxology, Vol, 2C, 3rd ed., Clayton, G. O. and Clayton F. E.y Eds., John Wiley \& Sons, New York, 1982, 4528. With permission. 
possible impacts on public health. Briefly, these attributes pertain to the following:

1. Availability - methanol precursors ( $\mathrm{CO}$ and $\mathrm{H}_{2}$ ) are available from a variety of carbonaceous sources, particularly coal, which is in abundant reserve in the U.S.

2. Distribution - the systems already in place for storage and transport of petroleum products are also able to handle alcohol fuels.

3. Fleet adaptability - currently used gasoline and diesel engines, with varying amounts of modification, can be converted into efficient methanol-burning engines; also, in-use gasoline engines are adaptable to gasoline-methanol blends.

4. Air quality - emissions from methanol-fueled vehicles are expected to result in ambient concentrations of criteria pollutants no greater than, and very likely, lower than those that result from gasoline or diesel emissions.

\section{B. Exposure to Methanol Vapor from Vehicles}

The critical value of exposure assessments to the characterization of environmental impacts on public health is fully recognized. ${ }^{9}$ A limited number of studies conducted by the EPA already have provided data on the ambient concentrations of methanol vapor expected under a range of vehicle and traffic conditions. ${ }^{1,3,4}$ These data, though not yielding detailed time and activity exposure analyses, have identified situations in which maximal, and perhaps toxicologically relevant, exposures are likely to occur.

The basic approach of these studies is to characterize lightand heavy-duty fleet emissions, and, with air quality modeling programs, use these data to compute expected ambient concentrations of methanol. In the initial steps, exhaust and evaporative emissions from individual vehicles are characterized under various conditions related to both driving cycle and the maintenance level of the vehicle. These data may be derived directly from laboratory testing and measurement of emissions from sample vehicles. Alternatively, emission values may be based on design targets or pre-set certification standards with offset (i.e., correction) factors applied to project actual in-use performance. Offset factors may reflect expected changes in emissions associated with tampering with emission control devices or malfunctions resulting from either lack of maintenance or from random causes.

The next objective is to translate vehicle-specific emissions into ambient concentrations of methanol vapor. For one important scenario, the personal garage, the emission characteristics of solitary vehicles (not fleets), garage size, and ventilation rates are the key determinants of methanol concentrations.

For traffic and parking garage situations, characterizations of entire fleets are essential to project air quality data. The EPA has developed MOBILE3, a data base program that helps meet this need. MOBILE 3 continually updates detailed profiles

of the composition and emissions of in-use gasoline and diescl fleets and allows for projecting fleet characteristics into the future. The data in the program include miles traveled per vehicle type and model year. For the calculation of total fieet emissions, MOBILE3 factors in variables, such as vehicle deterioration, that may effect the final emissions inventories. The data generated on methanol vapor concentrations, described below and in Tables 2 and 3 , are extracted from the air quality models developed for gasoline and diesel fleets.

The EPA studies have modeled methanol exposure levels that may occur in specific situations representative of the full range of vehicle use and traffic fiow. For example, the typical street canyon scenario that is modeled calls for a sidewalk exposure next to a 4-lane street with a traffic load of 800 vehicles per hour; in the severe case, the street is 6 lanes with 2400 vehicles per hour.

\section{Table 2}

Estimated In-Use Ambient Methanol Concentrations for Traffic Scenarios and Public Parking Garages $(100 \% \text { Fleet Penetration })^{\mathrm{a}}$

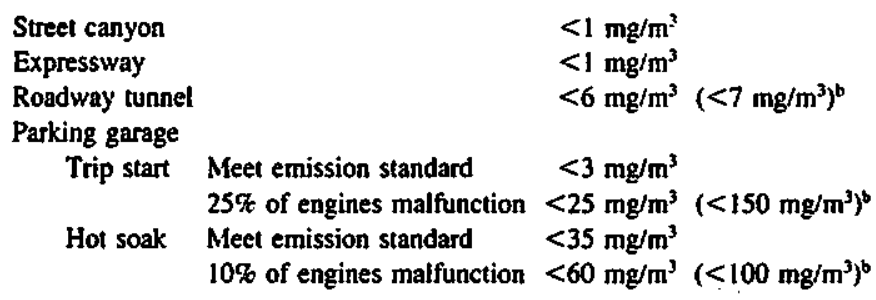

Note: For a fuller explanation of these data, see the 1987 HEI report on methanol vapors.

- 1985 EPA estimate.'

- 1988 EPA estimate.

\section{Table 3}

\section{Estimated Peak In-Use Ambient Methanol Concentration for Personal Garages and Service Station Refueling (Solitary Vehicles) ${ }^{a}$}

\author{
Personal garage \\ Engine idle Meet emission standard \\ Engine malfunction \\ Hot soak Meet emission standard \\ Engine malfunction \\ Refueling

$$
\begin{aligned}
& <2.9 \mathrm{mg} / \mathrm{m}^{3} \\
& <100 \mathrm{mg} / \mathrm{m}^{3}\left(<650 \mathrm{mg} / \mathrm{m}^{3}\right)^{\mathrm{b}} \\
& <50 \mathrm{mg} / \mathrm{m}^{3} \\
& <240 \mathrm{mg} / \mathrm{m}^{3}\left(<150 \mathrm{mg} / \mathrm{m}^{3}\right)^{6}
\end{aligned}
$$$$
<30-50 \mathrm{mg} / \mathrm{m}^{3}
$$

Nore: For a fuller explanation of these data, see the 1987 HEI report on methanol vapors.' Exposure in the personal garage scenario is brief. probably not lasting more than $15 \mathrm{~min}$.

- 1985 EPA estimate.

- 1988 EPA estimate. 


\section{Critical Reviews in}

For personal garages, vehicle warm-up tine influences the extent of potential exposure during the idle cycle; e.g., in the model, a typical warm-up interval for moderate weather conditions is $30 \mathrm{~s}$, and is 5 min during severe winter conditions (for both, the garage door is considered to be open). During personal garage hot-soak (evaporation from a hot engine after it has been turned off), the relative severity of exposure is a function of the garage size and air exchange rate. For parking garages, inflow and outflow rates of traffic, as well as facility size and ventilation, all determine idle and hot-soak concentrations.

Tables 2 and 3 display the methanol concentrations expected under the conditions described above. Two sets of values are given, the original EPA estimates for methanol exhaust and evaporative emissions data ${ }^{1}$ and an updated analysis (in parentheses) based on further testing of evaporative emissions. ${ }^{4}$ It should be emphasized that these data represent the results of limited testing of prototype and first generation light-duty methanol-fueled vehicles that did not have engines optimized for methanol. The values in Table 2 for roadway traffic scenarios represent combined light- and heavy-duty fleets; the data describing personal and parking garage scenarios represent exposures from only light-duty vehicles.

The tables show that maximal exposures to evaporative emissions are expected in the garage scenarios, particularly in the personal garage. There is considerable variability in the engine idle and hot-soak data when one compares the 1985 and 1988 analyses. ${ }^{1.4}$ These differences are due in part to different test procedures and the lack of a standard engine design. For the hypothetical case of a malfunctioning vehicle (i.e., one with a disabled canister) in a poorly ventilated personal garage, methanol concentrations produced by hot-soak emissions were projected in 1985 to be as high as $240 \mathrm{mg} / \mathrm{m}^{3}$ (Table 3). This estimate was reduced to $150 \mathrm{mg} / \mathrm{m}^{3}$ in the 1988 analysis. ${ }^{4}$ In the latter publication, the highest methanol concentrations were predicted for idling methanol-fueled vehicles in private garages (5-min idle, garage door open). ${ }^{4}$ This methanol emission estimate for engines idling inside of personal garages does not apply to more advanced vehicles with engines optimized for methanol.

In most cases, however, personal garage exposures will be brief, lasting only for the period that the operator occupies the garage during idle or hot-soak, perhaps a matter of minutes. For traffic situations (Table 2), methanol concentrations are generally much lower (less than $6 \mathrm{mg} / \mathrm{m}^{3}$ ) than in garages, with maxima predicted for roadway tunnels.

All scenarios except the personal garage assume $100 \%$ penetration of methanol-fueled vehicles into the fleet. Thus, all methanol values in Table 2 scale linearly with penetration fraction. Despite the brief exposure interval, the personal garage scenario is important not only because it represents the highest exposure level, but also because the methanol concentration is independent of penetration. Although the fleet values (Table
2) may not be achieved for decades, if ever, those for personal garages (Table 3) are projected for the individuals driving methanol-fueled cars and using personal garages at any level of penetration. Therefore, the potential exposures in personal ga. rages may be of more immediate concern.

One final exposure situation that merits attention is service station refueling (Table 3). According to EPA estimates, a typical methanol fill-up will result in about 3 to $4 \mathrm{~min}$ of exposure to between 33 and $50 \mathrm{mg} / \mathrm{m}^{3}$ of methanol. ${ }^{3}$ For self. service customers, such exposures may occur once or twice weckly, but for station attendants exposure will be much more frequent.

For reference purposes, the American Conference of Gov: ernmental Industrial Hygienists (ACGIH) threshold limit value (TLV) for exposure to methanol averaged over an 8-h work day is $260 \mathrm{mg} / \mathrm{m}^{3} .{ }^{10}$ This value has been designated for working populations and not for the general public, for whom the philosophy of standard-setting differs.

\section{TOXICITY OF METHANOL}

\section{A. Background}

In the 1890s, the use of wood alcohol increased significantly, and its acute toxicity was fully realized shortly thereafter. Previously, impurities retained in its distillation process rendered wood alcohol a vile-tasting and foul-smelling substance. Human exposures to wood alcohol and its vapors consequently were limited, and reports of intoxication, therefore, were very rare. The introduction of an inexpensive deodorization process during the 1890 s increased greatly the market for wood alcohol as a commercial product and as a solvent for use in the workplace. It was sold in stores as a pure substance under various? commercial names such as Columbian Spirits, Eagle Spirits, and Lion d'Or and was included as an ingredient in many other consumer products such as witch hazel, Jamaica ginger, vanilla extract, and perfumes. "1.12 Perhaps the most notorious use of wood alcohol was, and continues to be, as an adulterant in alcoholic beverages, a practice that has led to large-scale ep. isodes of poisonings since the turn of the century. ${ }^{13-17}$

In parallel with its spread in the consumer market place, wood alcohol became a widely used substance in the work: place. Tyson and Schoenberg reviewed data from the 1904 , U.S. census and tallied nearly two million workers in occu-is pations in which wood alcohol was used. ${ }^{18}$ Those most heavilyy represented included painters, glaziers, and varnishers $(278,000)$; launderers $(386,000)$; boot and shoemakers $(200,000)$; and printers and lithographers $(155,000)$.

The dramatic increase in wood alcohol distribution and use coupled with an almost universal ignorance concerning its toxic potential led quickly to an accumulation of case reports describing wood alcohol poisonings. In 1904, Wood and Buller published an oft-quoted series of 235 case studies that char acterized many of the key presenting features of acute methand 


\section{Toxicology}

poisoning. ${ }^{19.20}$ Bricfly, about a day after exposure, victims are stricken with visual disturbances and an array of incapacitating physical symptoms that may lead to coma and death. Wood and Buller and others in the medical community sounded alerts concerning wood alcohol and lobbied in the medical literature for social and legislative actions to control access to wood alcohol and its use. ${ }^{18.21 .22} \mathrm{~A}$ vast majority of poisonings in Wood and Buller's reports, and in the many wood alcohol/methanol incidents recorded since, have occurred from drinking adulterated beverages or wood alcohol products. In the largest single episode, Bennett et al. describe a case that occurred in Atlanta in 1951 when, within a 5-day period, 323 people ingested bootlegged whisky contaminated with methanol; 41 of these poisonings were fatal. ${ }^{15}$

Litovitz recently reviewed the acute methanol exposure cases reported in the U.S. ${ }^{23}$ In 1987,1601 methanol poisonings were reported to the American Association of Poison Control Centers. Half of these individuals required hospitalization and the death rate was $0.375 \%$. According to Litovitz's estimates, a rough approximation of the actual annual U.S. incidence of methanol poisoning in 1987 would be 4 times greater than this figure, or about 6400 cases. Comparable 1987 U.S. figures for gasoline poisonings are 52,000 gasoline exposures and 35,000 gasoline ingestions. The gasoline fatality rate in 1987 was $0.015 \%$.

Although oral ingestion dominates historically as the most frequent route of poisoning, the literature also substantiates that percutaneous absorption of methanol liquids or inhalation of its vapors are as effective as the oral route in producing methanol acute toxic syndrome. ${ }^{19,20,24}$ Tyson and Schoenberg counted about 100 cases reported up to 1912 of amblyopia (impairment of vision) and death from inhalation of wood alcohol vapors. ${ }^{18}$ Referring to the case literature on wood alcohol inhalation Ziegler wrote: 22

\footnotetext{
The majority of these cases occur from occupational exposure to the fumes. The painter uses it as a cleansing fluid or as a cheap diluent to cut his shellac in order to vamish the interior of large beer vats, closets or closed room. Two of Tyson's (1912) patients finally succumbed to the slow poisoning. ${ }^{25}$ The hatter mixes it with shellac to stiffen the nap or straw blanks. The dyer of leathers uses it to dilute the colors; the maker of shoe polish adds it to the paste; the brass finisher uses it in the lacquer, and the maker of rubber tires mixes the mass with it. If ventilation is very free, the danger will be lessened; but open air exercise at frequent intervals should be required for every such employee.
}

\section{B. Acute Toxicity: Description}

Nearly all of the available information about methanol toxicity in humans concerns the consequences of acute exposures.* This information is based on clinical case studies re-

"In this paper, the terms acute and chronic refer to the time-course of exposure,
rather than to the time-course of the appearance of effects. The reader should
bear this distinction in mind as the best-characterized effects of methanol appear
after a latent period of about a day following a single (i.e., acute), large
exposure and may continue to develop or persist for days, weeks, or longer. corded since the turn of the century and, more recently, on laboratory experiments that employ valid animal models of human toxicity. The few reports in the human case literature conceming repeated or prolonged exposures suggest that clironic and acute effects may share similar qualitics. Therefore, a description of the acute toxic properties of methanol is appropriate to the objectives of this paper.

Acute methanol toxicity in humans evolves in a fairly welldefined pattern. A toxic exposure results initially in a transient, mild depression of the central nervous system (CNS). An asymptomatic latent period follows and may last from several hours to 2 or more days, although 12 to $24 \mathrm{~h}$ is most common. ${ }^{15.26}$ The latent period gives way to the onset of a syndrome that consists of an uncompensated metabolic acidosis with superimposed toxicity to the visual system. Physical symptoms typically may include headache, dizziness, nausea, and vomiting; these may be followed by severe abdominal pain and difficult, periodic breathing (Kussmaul breathing), which may progress to coma and death, usually from respiratory failure. ${ }^{27.28}$

In parallel with the onset of these symptoms, subjects experience visual disturbances that include blurred or indistinct vision and altered visual fields (often depression of the central field) and, in severe cases, total blindness. ${ }^{13.15}$ Impairment of the pupillary response to light usually accompanies the visual symptoms, and the extent of impairment is predictive of survival. Subjects with unresponsive, dilated pupils often succumb to the toxic syndrome, and those who survive suffer appreciable and, in many cases, permanent loss of vision.

Ophthalmoscopic examinations of methanol-poisoned victims show that hyperemia (i.e., a local increase in blood flow) of the optic disc is the earliest change that occurs in the retina; hyperemia accompanies the initial visual symptoms. ${ }^{17.29}$ Within a day, a white striated edema (an accumulation of an excessive amount of watery fluid) appears that projects into the surrounding retina from the optic disc, whose margin simultaneously acquires a blurred appearance; the papilla itself is not edematous. (The papilla, also called the nerve head, is the area where the nerve fibers of the retina converge to form the optic nerve.) The optic disc hyperemia usually subsides within a week, but edema in the region of the optic disc may persist for up to 2 months. The edema follows the course of major blood vessels and appears to be located mainly in the nerve fiber layer of the retina.

In the Atlanta epidemic, these opthalmoscopically visible changes were observed in $87 \%$ of patients with acute visual symptoms, and in all patients who developed permanent visual deficit. Furthermore, the severity of retinal edema was predictive of restoration of vision; mild edema resulted frequently in full recovery, and severe edema led invariably to permanent effects. ${ }^{29}$ Pallor of the optic disc is an end-stage sign of irreversible effects of the visual system and may appear 1 to 2 months after an acute methanol dosage (or possibly following 


\section{Critical Reviews In}

chronic occupational exposure to methanol vapors. ${ }^{15,19,20,22.25}$ The pallor indicates a loss of the blood supply to the head of the optic nerve and frequently reflects atrophy of the optic nerve. ${ }^{30}$

Autopsies from victims of lethal methanol poisonings have revealed gross pathology in the visceral organs, the lung, and the CNS, all of which involve a variety of edematous, hemorrhagic, and degenerative changes. ${ }^{\text {13-15,31-3.3 }}$ Several case studies report post-mortem signs of damage to the basal ganglia in the brain, specifically the putamen. ${ }^{11,33,34}$ This area of the brain participates in the control of gross intentional motor activities that are normally performed unconsciously. Damage to this area results in various motor disorders such as Parkinsonism and Huntington disease. A number of human studies have shown that survivors of severe methanol intoxication may suffer residual damage to the putamen and have associated motor disorders. ${ }^{33.36}$

Two facets of methanol toxicity that were appreciated quite early concern, first, the dose level of methanol that is hazardous to humans, and, second, the variable susceptibility to acute effects among individual people. Reflecting on his collection of case studies published with Buller, Wood stated in 1912:21

As in the case of several other poisons, some persons are largely immune so far as permanent damage to the organism is concemed. If ten persons drink, say, four ounces of Columbian spirits within three hours, all will have marked abdominal distress and four will die, two of them becorning blind before death. Six will eventually recover, of whom two will be permanently blind before death. With still larger doses, the proportion of death and blindness will be greater.

In this summary statement, 4 oz of Columbian spirits, or 95 $\mathrm{g}$ of methanol (Columbian spirits is basically pure methanol) is lethal to $40 \%$ of the cases; for a $70-\mathrm{kg}$ person, this dose is equivalent to about $1.4 \mathrm{~g}$ of methanol per kilogram of body weight $(\mathrm{g} / \mathrm{kg})$. This figure is consistent with currently accepted values for lethality, and 0.3 to $1 \mathrm{~g} / \mathrm{kg}$ is considered the range of a minimum lethal dose for untreated cases. ${ }^{26,33,37.38}$

Acute methanol poisoning patients with blood levels of methanof $\geqslant 50 \mathrm{mg} / \mathrm{dl}$ are generally regarded as requiring hemodialysis. ${ }^{39}$ In her recent analysis, Litovitz calculated that the dose of methanol required to achieve this blood concentration is very small, $0.4 \mathrm{~m} / \mathrm{kg}$ body weight. This corresponds to the ingestion of $4 \mathrm{ml}$ (less than a teaspoonful) of $100 \%$ methanol fuel by a $10-\mathrm{kg}$ (1-year old) child, $6 \mathrm{ml}$ by a 15-kg (3-year old) child, and $28 \mathrm{ml}$ (less than $1 \mathrm{oz}$ ) by a $70-\mathrm{kg}$ adult.

As mentioned earlier, the time to onset of symptoms among poisoned victims is quite variable, ranging from several hours to a few days. The variability of the effective dose is a prominent feature of acute methanol toxicity as well. ${ }^{13,19.20 .27} \mathrm{~A}$ case report of poisoning among American soldiers in 1945 states that for each patient admitted to the hospital, up to four others had taken equivalent amounts of methanol without seeking medical care. ${ }^{14}$ In the Atlantic epidemic, most patients claimed drinking about a quarter of a pint (approximately 125 cc) of "moonshine"; which consisted of $40 \%$ methanol. The" lowest lethal dose reported was "three teaspoons" (about 15 $\mathrm{ml}$ ), and the largest dose survived was about a half liter of this; mixture.

Variable susceptibility is a hallmark of human and animal responses to virtually all toxic substances. The elucidation of the root causes of variability is essential to evaluate the potential public health impacts of substances likely to be ubiquitous;: such as community air pollutants. Two general classes of fac. tors determine susceptibility: metabolic and physiologic char: acteristics that are inherent (e.g., age, sex, genetic determinants), and the effects of external influences such as lifestyle and exposure to other substances. In the case of methanol toxicity, susceptibility factors of both classes no doubt remain unidentified. Two factors known to influence sensitivity, the amount of ethanol ingested with methanol, and the dietary sufficiency of folate, are discussed below.

To date, modulators of susceptibility are described only for acute effects of methanol. Although these factors also may play roles in differential susceptibility to chronic effects, the list of factors that modify responses to methanol cannot be considered complete.

\section{Repeated or Prolonged Human Exposures to Methanol}

The information available suggests that extended human ex posures to methanol may cause effects qualitatively similar to those from relatively high levels of acute exposure. This in-: formation is based on a limited number of case reports and even fewer epidemiologic studies, although this literature suf, fers generally from the classic shortcomings that include un: known levels and/or durations of exposure.

The effects of prolonged exposure are qualitatively very? similar to those reported for acute cases, consisting of central nervous and visual disorders. The studies described are divided." into case reports and epidemiologic studies.

\section{Case Studies}

The first of these was a 1901 report of a man who became blind after periodic exposure to varnish dissolved in methanol ${ }^{40} \mathrm{t} f$ and the use of methanol to clean his face and arms over a period of 3 years (also reported in Wood and Buller, case A-25). ${ }^{19}$ The Wood and Buller series of case reports in 1904 k included several cases that indicated methanol toxicity frotis extended exposure: ${ }^{19.20}$ failed vision, headache, and vomiting in a man who dyed and cleaned clothes in alcoholic prepara: tions; length of exposure unspecified (Case B-66); deteriorating vision in a man who frequently drank Jamaica ginger (purtif methanol) as an alcoholic substitute; an acute dose took bis life (Case B-86); a woman who daily took three or four table spoonsful of Jamaica ginger went practically blind (Case B 89); a woman who, for weeks, used wood alcohol to heat herf 
theumatic bath and as a cleansing application to face and head presented with impaired vision and partial pallor of the optic nerve (Case C-2); visual loss occurred in a woman who, for two or three months, had used an alcohol-fueled lamp to heat water in a poorly ventilated space; she recovered after her doctor told her to cease exposure (Case C-4); a man who, for a living, varnished beer vats, used shellac cut with methanol, and experienced "constitutional symptoms" and "foggy vision" from inhaling the vapors; length of exposure unspecified (Case C-6); and a workman in a cabinet department who cleaned his hands in Columbian spirits to remove shellac suffered from impaired vision (Case C-9).

Severe visual effects were subsequently reported in men exposed to methanol vapor when methanol was used as a paint remover and for mixing shellac ${ }^{41}$ or for varnishing beer vats for periods of 3 to 5 days. ${ }^{21.25}$ In each of these instances, CNS symptoms (headache, dizziness, nausea, numbness) preceded or accompanied the development of visual symptoms. In a 1905 report, " CNS symptoms were described in two men who inhaled fumes from shellac dissolved in methanol, but no visual sequelae followed. In none of these reports was the actual level of methanol exposure determined or estimated.

Ziegler described a man who visited a china cement factory for 1 h each day. ${ }^{22}$ Methanol was found to be a constituent of the cement. The man had experienced, for several months, failing vision and contraction of visual fields. When visits to the cement factory were stopped, the man slowly recovered and then maintained normal vision. Ziegler also described a painter who inhaled fumes while varnishing an engine room in a submarine for 3 days. ${ }^{22} \mathrm{He}$ was "dizzy" the first day, "hilarious" the second, and "nervous" the third. He also suffered gastric pain and insomnia, soon followed by ptosis (drooping of the eyelid), and blindness. Ziegler also stated that these symptoms were associated with acidosis, although no clinical data were provided. As in the earlier cases, the actual level of exposure was not known.

Humperdinck, in $1941,{ }^{42}$ reported the occurrence of mild methanol intoxication with temporary blindness in one laborer employed in a nitrocellulose plant. This worker could presumably have experienced repeated exposures of 1600 to 10,900 $\mathrm{mg} / \mathrm{m}^{3}$ methanol, which was the amount measured in the air above the weighing station where the worker was employed. The authors noted, however, that over a 10 -year period, no other workers had reported any symptoms of methanol toxicity. Burk also described a case of occupational poisoning attributable to methanol vapor inhalation. ${ }^{43}$ This worker had been employed in the methyl alcohol department of a chemical pharmaceutical factory for 4 years and had previously complained of visual disorders and asthenia (weakness) of the hands and arms. Upon a 2-day exposure to methanol fumes while cleaning a boiler in which crude nicotinic acid was boiled with methanol, he experienced vertigo, nausea, and visual disorders. No information on the airborne concentration of methanol was pro- vided. Ophthalmoscopic examination showed edema of the optic disc of both eyes. After 5 weeks, full visual acuity returned.

\section{Epidemlology}

A snall number of epidemiology studies have been published on methanol exposure, but are generally documented inadequately. The earliest study involves 25 to 30 women who polished wooden lead pencils with varnish made from methanol; many washed their hands in the alcohol to remove the shellac. ${ }^{25}$ All of the women reported headaches, and some had gastric disorders during working hours; two reported visual disturbances. They frequently took breaks to get fresh air. The airborne concentration of methanol was unknown. Greenburg et al. studied 19 workers employed in the manufacture of "fused collars". ${ }^{44}$ These workers used solutions of three parts acetone to one part methanol to impregnate collars, which were then steam pressed. Concentrations of acetone and methanol in the work room were measured to be 96 to $108 \mathrm{mg} / \mathrm{m}^{3}$ and 29 to $33 \mathrm{mg} / \mathrm{m}^{3}$, respectively, and a "strong odor" of solvent was perceptible. The shortest period that any of these workers had spent fusing collars was 9 months, and the longest was 2 years. No CNS or visual anomalies in any of these workers were reported.

In 1955, Kingsley and Hirsch reported frequent and persistent headaches in clerical workers located close to "spirit" duplicating equipment that used methanol-based duplicating fluid. ${ }^{45}$ The most severe headaches were reported to occur in personnel who actually operated the equipment. The onset of symptoms coincided with the beginning of cooler weather, which required the closing of windows and doors, thus inhibiting ventilation. No visual effects or other permanent sequelae were reported. Kingsley and Hirsch measured methanol concentrations as high as $490 \mathrm{mg} / \mathrm{m}^{3}$ in the air surrounding the duplicating equipment after $60 \mathrm{~min}$ of operation, and approximately $130 \mathrm{mg} / \mathrm{m}^{3}$ about $10 \mathrm{ft}$ away from the device. ${ }^{45}$ The methanol concentration around the device in question always exceeded $260 \mathrm{mg} / \mathrm{m}^{3}$. No information on the number of employees exposed or affected, or on the actual duration of methanol exposure, was provided in this report.

More recently, the National Institute for Occupational Safety and Health (NIOSH) reported that $45 \%$ of "spirit" duplicating machine operators at the University of Washington experienced "some" symptoms (blurred vision, headache, nausea, dizziness, and eye irritation) consistent with the toxic effects of methanol. ${ }^{46}$ Apparently, no information on the actual length of duration of methanol exposure among these employees was collected. When NIOSH measured airborne methanol concentration for $25 \mathrm{~min}$ in the vicinity of the duplicators when windows and doors were open, the average was $1330 \mathrm{mg} / \mathrm{m}^{3}$.

In 1984, Frederick et al. of NIOSH published a study of teacher aides who worked at or near spirit duplicators that used a 99\% methanol duplicator fluid. ${ }^{47}$ The exposures ranged from 
$1 \mathrm{~h} /$ day for 1 day/week to $8 \mathrm{~h} / \mathrm{d}$ for 5 days per week, and had been occurring presumably for about 3 years. Ventilation was either inadequate or totally lacking. Since the introduction of the equipment, the aides began to experience headaches, dizziness, and eye irritation while operating the machines or working near them. Breathing zone samples of 15-min duration near 21 operating machines contained between 475 and $4000 \mathrm{mg} / \mathrm{m}^{3}$ (1380 $\pm 745(\mathrm{SD}) \mathrm{mg} / \mathrm{m}^{3}$ ) of methanol vapor; 15 of these samples exceeded NIOSH $15-\mathrm{min}$ standard of $1050 \mathrm{mg} / \mathrm{m}^{3}$ (or $800 \mathrm{ppm}$ ). The existing ventilation, when operating, lowered the levels around selected machines by an average of $58 \%$ (range: 7 to $89 \%$ ); even so, methanol concentrations exceeded the $260 \mathrm{mg} / \mathrm{m}^{3}$ 8-h standard for at least half of the duplicators tested. When NIOSH-fabricated enclosures were added, the unventilated values dropped by an average $96 \%$ (range: 90 to 99\%). The aides also were exposed while collating and stapling papers impregnated with the fluid up to $3 \mathrm{~h}$ earlier, and these exposures ranged from 235 to $1140 \mathrm{mg} / \mathrm{m}^{3}$.

A health questionnaire survey was conducted among 84 teacher aides and 302 teachers, who served as a comparison group. Teachers, although working in the same school, probably spend significantly less time near the duplicators (and less time collating) than the aides. All aides and teachers surveyed were female. Of the aides, 66 (79\%) responded (mean age 39.8); their responses were compared to those of 66 randomly selected teachers (mean age 37.5). The respondents provided data on the prevalence of 22 specific symptoms that they experienced in the month preceding the survey. The list included symptoms considered both related and unrelated to the effects of methanol. Among the aides, 4 of the 22 symptoms were significantly higher and all were associated with methanol toxicity: headache, dizzy/lightheaded, blurred vision, and nausea/upset stomach (see Table 4). No other symptoms registered significant differences between the two groups, although positive trends appeared evident for burning/itching/tearing of the eyes (17 of 66 aides vs. 8 of 66 teachers) and skin problems ( 7 vs. 1 , respectively).

\section{Table 4}

\section{Symptoms Significantly $(p<0.05)$ More Prevalent in} Teacher Aides than Teachers

\section{Symptom}

Headache

Dizzy/lightheaded

Blurred vision
Nausea/upset stomach

$\begin{array}{lc}\text { Teachers } & \text { Aides } \\ (n=66) & (n=66)\end{array}$

12
1
1
4

Ratio

2

20

15

3
Adapted from Frederick, L. J., Schulte, P. A., and Apol, A., Investigation and control of occupational hazards associated with the use of spirit duplicators. Am. Ind. Hyg. Assoc. J., 45, S1, 1984.
Criteria were established to define a positive case of meth anol toxicity (Table 5). With these criteria, 30 aides and 16 teachers qualified, a difference that is significant $(p<0.025)$, Finally, the investigators determined that the case attack ratey increased, for both aides and teachers, as a function of percent of time spent at the duplicator each week.

This study clearly stands apart from all others available be cause it provides data on ambient concentrations, duration of exposure, health status, and the relation between case attack rate and work-time exposed. The results suggest that chronic effects may occur when methanol concentrations exceed the TLV of $260 \mathrm{mg} / \mathrm{m}^{3}$. The effects in this study are similar in nature but appear less severe than those from acute intoxication.

Although of value, this study, nevertheless, has several fea-: tures that prevent one from drawing a definitive causal association between methanol exposures and the effects reported. First, the study was conducted in response to the teacher aides? complaints, and thus the questionnaire data may have contained responder bias. Second, the data were based on symptom re porting only, whereas additional clinical investigations may? have helped to further define the effects. Finally, information: was not presented to exclude the possibility that the symptoms might have arisen from other chemicals or solvents that may have been in the teachers aides' environment. Despite these shortcomings, the study by Frederick et al. is of relevance. in

Other studies have measured methanol and formate in the blood and urine of workers exposed during an 8-h day to between 100 and $200 \mathrm{mg} / \mathrm{m}^{3}$ of methanol vapors. ${ }^{48.49}$ Although these studies were predicated on issues of occupational health related to methanol exposure, no health data were provided In none of these studies did the investigators imply that the workers studied had suffered health effects.

\section{Russian Clinical Studles: Low-Level Exposures}

Russian investigators published papers in 1959 and 1967 that claimed neurobehavioral effects in humans exposed to very low exposure levels of methanol vapors (less than $12 \mathrm{mg} / \mathrm{m}^{3}$ ), In the first paper, Chao measured the threshold of olfactory

\section{Table 5}

\section{Criteria for Defining Methanol Toxicity}

\author{
I. Visual changes or blurred vision \\ 2. One acute symtom (headache, dizziness, numbness, giddiness, \\ nausea, or vomiting) and one chronic symptom (usually tired, \\ muscle weakness, trouble sleeping, irritability or poor memory) \\ 3. Two acute symptoms \\ 4. Three chronic symptoms
}

Adapted from Frederick, L. J., Schulte, P. A., and Apol, A., Investigatio and control of occupational hazards associated with the use of spirit duplicaton Am. Ind. Hyg. Assoc. J.. 45, 51, 1984. 


\section{Toxicology}

perception and dark adaptation (or light sensitivity). ${ }^{50}$ The second paper, by Ubaydullayev, ${ }^{31}$ included both of these measures in addition to the EEG conditioned reflex threshold. In the olfactory studies, Chao (13 subjects) and Ubaydullayev (25 subjects) reported the range for minimum detectable methanol concentrations of 4.3 to 11.1 and 3.7 to $10.5 \mathrm{mg} / \mathrm{m}^{3}$, respectively, and the range for maximum imperceptible concentrations of 3.7 to 10.5 and 3.9 to $9.7 \mathrm{mg} / \mathrm{m}^{3}$, respectively. Minimum levels of methanol that affected dark adaptation were $3.3 \mathrm{mg} / \mathrm{m}^{3}$ for Chao (three subjects) and $3.5 \mathrm{mg} / \mathrm{m}^{3}$ for Ubaydullayev (three subjects). Finally, the latter investigator found the threshold for EEG conditioned reflexes at $1.17 \mathrm{mg} / \mathrm{m}^{3}$ (two of six subjects).

The results of these studies suggest that exposures of several minutes or less to very low concentrations of methanol stimulate visual and peripheral olfactory receptors, and may influence the processing of stimuli in the CNS. The two studies, published 8 years apart, produced consistent data on olfactory thresholds and qualitatively similar data on dark adaptation.

Several problems call the results of these studies into question. Briefiy, subject descriptions were not provided, and neither were several important details concerning data acquisition. For example, no information was provided on the specific time points selected for testing dark adaptation, or on the length of exposure in the EEG conditioning test. The purity grade of methanol used was not described, which leads to a suspicion that impurities in the methanol could have confounded the determination of olfactory thresholds and, possibly, the measures in the other two experiments. Also, these investigators did not discuss the manner in which methanol concentrations were measured, another potential source of error. Several factors of the two dark adaptation studies display conflicts that cannot be resolved. Finally, the dark adaptation and EEG effects occurred at exposure conditions that would contribute a negligible amount to the background levels of methanol in the body.

\section{E. Background Body Burdens of Methanol and Formate}

Exposures to substances in the environment often contribute to a preexisting body burden of that substance or its metabolites, found in people classified as "unexposed." For example, exposures to the airborne pollutants, carbon monoxide, and manganese contribute to background levels that would be found in people breathing clean air.

The two most prominent sources of background body burdens for methanol and formate are diet and natural metabolic processes. Sedivec et al. reported a mean blood methanol level of $0.73 \mathrm{mg} / \mathrm{l}$ in 31 unexposed subjects (range: 0.32 to 2.61 mg/l), ${ }^{52}$ and Eriksen and Kulkarni measured a mean of 0.25 $\mu \mathrm{g} / \mathrm{l}$ in expired breath of 9 "normal" people (range: 0.06 to $0.45 \mu \mathrm{g} / \mathrm{l}) .{ }^{53}$ Methanol is available in the diet from eating fresh fruits and vegetables or from drinking fruit juices (average of $140 \mathrm{mg} / \mathrm{l}$ ); range: 12 to $640 \mathrm{mg} / \mathrm{l}$ ) and fermented beverages (up to $1.5 \mathrm{~g} / \mathrm{l}$ ).${ }^{54}$ More recently, aspartame, an artificial sweetener, has become a part of most diets. In the gut, aspartame hydrolyzes, and $10 \%$ of its molecule, by weight, becomes free methanol that is available for absorption. ${ }^{35}$ According to recent estimates, excluding carbonated beverages, daily aspartame intake will average from 3 to $11 \mathrm{mg} / \mathrm{kg}$, with the 99 th percentile ingesting up to $34 \mathrm{mg} / \mathrm{kg}$ (i.e., $3.4 \mathrm{mg} / \mathrm{kg}$ methanol). ${ }^{55} \mathrm{Car}-$ bonated beverages contain about $555 \mathrm{mg}$ aspartame per liter, which means that drinking a $12 \mathrm{oz}(354 \mathrm{cc}$ ) beverage is roughly equivalent to a methanol intake of $20 \mathrm{mg}$. In addition, methanol is generated metabolically by the action of a nethylitransferase enzyme system. This system methylates acceptor proteins by the action of protein carboxyl methylase and hydrolyzes protein methyl esters (by the action of protein methyl esterase), which releases free methanol. ${ }^{56,57}$ The relative contributions of diet and metabolism to the methanol body burden has not been established.

Formate, a toxic metabolite of methanol discussed below, is present in the blood at background levels that range from 3 to $19 \mathrm{mg} / 1(0.07$ to $0.4 \mathrm{mM}){ }^{48.58}$ Formic acid is a natural ingredient of various foods such as honey (2 to $200 \mathrm{mg} / 100$ g), fruit syrups (65 to $163 \mathrm{mg} / 100 \mathrm{~g}$ ), and roasted coffee (200 to $770 \mathrm{mg} / 100 \mathrm{~g}$ ), and also is used as a preservative. ${ }^{59}$ Formic acid also participates in several metabolic processes; for example, it is a product of the metabolic degradation of several amino acids, including histidine and tryptophan, and also serves as a precursor for a variety of macromolecules. ${ }^{59.60}$ Perhaps most germane to the present discussion, formate is a metabolite of methanol and is metabolized in the folate pathway, as discussed in detail in Section IV. The relative contributions of diet, metabolism, and methanol breakdown to the formate body burden are unknown.

The reader should bear in mind that all projections of body burdens of methanol calculated in the following section of this report reflect only the environmental contribution. For purposes of evaluation and perspective, these contributions should be compared to background levels.

\section{F. Development of Animal Models}

Extensive clinical and research efforts in this and other countries have been invested to understand the toxicological, biochemical, and metabolic nature of methanol intoxication, and to improve the management of methanol-poisoned patients. In the early part of this century, the prognosis for methanol intoxication was poor, and available treatments were ineffectual. Since the 1940s, clinical advances have quickened, and the loss of vision and life from methanol exposure has significantly abated. Today, three therapeutic modes generally are used, usually in concert to alleviate the signs and symptoms of acute methanol toxicity. They are (1) alkali treatment to restore acid- 
base balance, (2) cthanol treatment to retard the metabolism of methanol, and (3) hemodialysis to accelerate the clearance of methanol and formate from body fluids. (Peritoneal dialysis, less effective than hemodialysis, is also used on occasion.) Other potential treatments are still in the research or trial stages. ${ }^{28}$

For the half century that followed the 1904 reports of Wood and Buller, a major impediment to understand and treat methanol poisoning was the lack of awareness that only non-human primate species present a model of acute human methanol toxicity. In their report on ocular effects in the Atlanta epidemic, Benton and Calhoun wrote: "It is unfortunate that laboratory animals do not respond to this agent in a manner similar to the human. Acidosis almost never develops, and the animals do not often appear to go blind."29 In 1955, Roe, who in the 1940s first advocated ethanol therapy, wrote: "It is a waste of time to attempt to investigate the mechanism of the toxic effects of methanol in man by means of animal experiments until it is clear why animals do not develop more than a moderate degree of acidosis." ${ }^{26}$ The term "animal" in both of these quotes refers to non-primate species. Most animal research to that time focused on dogs, rabbits, rats, and mice; the few results from experiments on non-human primates did not emerge as unique.

In 1955, Gilger and Potts published a landmark paper that, for the first time, established the non-human primate as the model of choice for acute methanol toxicity in humans. ${ }^{61}$ The introduction to the paper provides an excellent review and critique of the extant literature on methanol toxicity in animals and indicates the technical inadequacies of this literature and the misconceptions it helped to create. In the experiment, Gilger and Potts exposed rats (Sprague-Dawley), rabbits, dogs, and rhesus macaque monkeys to a range of methanol doses. ${ }^{61}$ (They also exposed mice as reported in a previous paper. $)^{62}$ Gilger and Potts observed that (1) the lethal dose for nonprimates was two to three times higher than the $3 \mathrm{~g} / \mathrm{kg}$ lethal dose reported for the monkeys (i.e., 6 to 10 times higher than lethal doses in humans), and (2) of all the species tested, only non-human primates experience a sequence of early inebriation, then a day latency followed by the toxic syndrome characteristic of humans (acidosis, some ocular toxicity), which preceded their death; the other species developed an initial narcosis from which they either survived or died, and acidosis was not a prominent feature of this toxicity.

In follow-up papers, these investigators studied in non-human primates methanol-induced pathology and the effects of both bicarbonate (i.e., base) and ethanol therapy on the clinical course following lethal-if-untreated doses of methanol. ${ }^{63-66}$ (All studies used rhesus macaques except one, ${ }^{66}$ which used both thesus and grivet monkeys.) Both treatments effectively prevented death, as they do in humans, but bicarbonate therapy did not suppress the appearance of retinal edema. However, no signs of ocular toxicity occurred in ethanol-treated animals. These findings are consistent with the principles that (1) acidosis is the proximal cause of general symptoms and death in human methanol intoxication and (2) blocking the metabolismiln of methanol prevents simultaneously the acidosis and the gent eration of metabolites toxic to the visual system.

The legitimacy of the non-human primate model has sinco been confirmed ${ }^{67.68}$ and has enabled a systematic explorationg of the metabolic bases, kinetics, and mechanisms of methanol's acute toxic syndrome, all of which are covered in greater depthi in Section IV. Research in lower species, primarily rats has, nonetheless, been integral to the refinement of the non-humani primate model. The contrast between the metabolic machineryth of rats and non-human primates has helped pinpoint some im portant biochemical characteristics that influence the sensitivity or resistance to methanol poisoning. Moreover, these advances in animal models lessened the absolute reliance on human data which are usually collected in the heat of a medical emergency. Finally, non-primates may remain appropriate models in stud. ies that seek to understand the direct alcoholic effects of methis anol.

\section{G. Studies of Repeated or Prolonged Methanol Exposure in Non-Primates}

\section{Rodents}

Because of the superiority of non-human primates as ext perimental models of human methanol toxicity, few experit ments on the biologic effects of methanol have been conducted using rodents in the past 30 years. In a 1976 study by Skirkojo et al. (a Russian study cited in Reference 6), rats received orall doses of 10,100 , or $500 \mathrm{mg} / \mathrm{kg} /$ day for 1 month and were reported to show liver changes characterized by focal proteinity degeneration of hepatocytic cytoplasm, changes in the activitim of some microsomal enzymes, and enlarged hepatic cells. (嚁) another Russian study, rabbits exposed to $61 \mathrm{mg} / \mathrm{m}^{3}$ methano for 6 months [duration of exposure per day not given] weri reported to have ultrastructural changes in the photoreceptof cells and Muller fibers [Vendilo et al. 1971, a study cited in Reference 6].) The reliability of either of these reports remain ${ }^{3}$ to be established through critical review of translated articlest In an English article, White et al. reported that exposure of rats (Sprague-Dawley) to airborne methanol concentrations of 260,2600 , or $13,000 \mathrm{mg} / \mathrm{m}^{3}$ for as long as 6 weeks caused rito signs of lung inflammation or irritation. ${ }^{69}$ Histologic analyse. of lung tissue were not conducted.

In a subchronic inhalation study, Sprague-Dawley rats wero exposed for 4 weeks ( $6 \mathrm{~h} /$ day, 5 days/week) to 650,2600 and $6500 \mathrm{mg} / \mathrm{m}^{3}$ of methanol vapor. ${ }^{70}$ The animals were observe twice daily for signs of toxicity, were given detailed physicin examinations each week, and ophthalmoscopic examination at pre-test and at termination. After sacrifice, the animaly organs were examined and weighed, and selected tissues frow all animals in the control and high-exposure groups were ex amined microscopically. These included nasal turbinates, tra 
chea, lungs, esophagus, liver, and the eye and optic nerve. The investigators report no effects, except for increased discharges about the eyes and nose. The only dose-related effect observed was mucoid nasal discharge, which the investigators believe is reflective of upper respiratory tract irritation. Although stating that this effect was dose-related, Andrews et al. provide no dose-effect data on this finding. No other treatmentrelated effects were observed in this study.

Neurobehavioral toxicity associated with exposure to low concentrations of methanol in laboratory rats was reported in two studies in the Russian literature. ${ }^{50.51}$ These studies raised questions with regard to potential effects of methanol at expected ambient levels. Chao exposed groups of ten rats (of unspecified sex and strain) to methanol vapor at concentrations of $0,1.77$, and $49.77 \mathrm{mg} / \mathrm{m}^{3}$ for $12 \mathrm{~h} /$ day ("excluding days off") for 3 months. ${ }^{50}$ The relationship of flexor to extensor chronaxy was measured at unspecified intervals. According to a review of behavioral toxicology paradigms used in the U.S.S.R.," "chronaxy is the minimum time necessary for a stimulus of twice the absolute threshold intensity to evoke a response" and is measured as muscle contractions in response to an electric current applied to the animal's hind leg. Normally, the flexor chronaxy is shorter than the extensor chronaxy, and their ratio is stated to be a relatively stable one. According to the NIOSH review, certain toxic agents have been found to reverse this relationship. ${ }^{71}$ Although the chronaximetry method as used by Chao and Ubaydullayev (see below) is poorly described in both published studies, the methodological details provided are consistent with the standardized methodology summarized by NIOSH. ${ }^{72}$

Chao reported that the average chronaxy ratio for rats in the high dose group significantly differed from that in the controls at week 8 of exposure. ${ }^{30}$ The average chronaxy ratio was stated to have retumed to normal during the recovery period. Effects in the low-dose group were reported to be insignificant. Although the investigators reported that dose groups consisted of ten animals per group, they did not indicate the number of animals tested per testing interval, or the frequency of measurement of chronaxy ratios. Data were presented only graphically and actual chronaxy ratios and results of statistical analyses were not provided.

Chao also reported certain histopathological changes in the high-dose group but not in the low-dose group. ${ }^{50}$ The lesions included "poorly defined changes in the mucous membranes of the trachea and bronchi", hyperplasia of the submucosa of the trachea, slight lymphoid infiltration, swelling and hypertrophy of the muscle layer of pulmonary arteries, slight degenerative changes to the liver, and changes in the neurons of the cerebral cortex. A list of tissues examined histopathologically, the number of animals per group subject to pathological examination, and the incidence of tissue lesions were not provided.

Ubaydullayev exposed groups of 15 male rats (strain not specified) to methanol at average air concentrations of $0,0.57$, and $5.31 \mathrm{mg} / \mathrm{m}^{3}$ for $24 \mathrm{~h} /$ day for 90 days. ${ }^{51}$ Motor chronaxy ratios were measured at 10-day intervals in five rats per group. Ubaydullayev reported that the high-dose group "manifested statistically reliable changes" in the motor chronaxy ratio beginning at week 6 and that the ratio returned to normal by the end of the recovery period (length of recovery period is not specified). Average values for the chronaxy ratios for the three groups over the study were presented graphically, but the actual data and statistical analyses were not provided.

Urinary coproporphyrin levels, whole blood cholinesterase activity, and levels of total protein and protein fractions in blood serum also were measured in five rats of each group. ${ }^{\text {st }}$ In the high-dose group, the investigator reported a decrease in urinary coproporphyrin levels and cholinesterase activity. Blood serum albumin levels dropped and levels of beta- and gammaglobulins increased in the high-dose group compared to the controls. These parameters were reported to have retumed to normal after cessation of exposure. No effects were observed in the low-dose group. The investigator presented average values for the control, low-dose, and high-dose, but did not provide any statistical analysis of the data.

The results reported by Chao and Ubaydullayev do not provide adequate evidence of an association between neurobehavioral effects and low-level exposure to methanol in laboratory animals. Both studies are limited by the use of small numbers of animals per dose group, as well as insufficient reporting of experimental methods, study results, and statistical analyses. Furthermore, the biological significance of changes in the chronaxy ratio is uncertain. Although measurement of the chronaxy ratio in rats appears to be a standard protocol for assessing neurobehavioral toxicity in Russian research, it is not a toxicological measure emphasized in the U.S. literature.

Three studies have been reported in which the reproductive or teratogenic effects of methanol in nonprimate species were investigated. Cameron et al. exposed mature male rats (Sprague-Dawley) for $8 \mathrm{~h}$ /day to airborne methanol concentrations or 260,2600 , or $13,000 \mathrm{mg} / \mathrm{m}^{3}$ for $1,2,4$, or 6 weeks and examined them for alterations in circulating free testosterone, luteinizing hormone (LH), and follicle-stimulating hormone (FSH). ${ }^{73}$ Significantly decreased levels of circulating free testosterone were observed among rats exposed to $260 \mathrm{mg} / \mathrm{m}^{3}$ for 2 and 6 weeks and to $2600 \mathrm{mg} / \mathrm{m}^{3}$ for 6 weeks. However, the high dose group $\left(13,000 \mathrm{mg} / \mathrm{m}^{3}\right)$ showed no change. The authors interpreted this as evidence that methanol exposure had lowered testicular production of testosterone. In addition, significant increases in circulating LH were observed after 6 weeks of exposure to $13,000 \mathrm{mg} / \mathrm{m}^{3}$. No changes in FSH levels were observed.

In a second study by the same group, rats were exposed to methanol vapors $\left(260 \mathrm{mg} / \mathrm{m}^{3}\right)$ for $6 \mathrm{~h}$ for either $I$ day or $I$ week. ${ }^{74}$ Serum testosterone levels were measured at the end of the exposure, and $18 \mathrm{~h}$ after exposure. In this experiment, 


\section{Critical Reviews In}

a significant depression was found in serum testosterone immediately after the first exposure, but not after 1 week of daily 6-h exposures to methanol vapors. If one examines these data together with the results of the original study, there is no consistent pattern of methanol-induced effects on serum testosterone levels. The serum concentration of testosterone was significantly reduced following 1-day, 2-weeks, and 6-weeks exposure to $260 \mathrm{mg} / \mathrm{m}^{3}$ methanol, but not after 1 or 4 weeks.

Nelson et al. administered $0,6500,13,000$, or $26,000 \mathrm{mg} / \mathrm{m}^{3}$ methanot to groups of approximately 15 pregnant SpragueDawley rats for $7 \mathrm{~h} /$ day on days 1 through 19 of gestation (for $26,000 \mathrm{mg} / \mathrm{m}^{3}$, days 7 through 15 only) ${ }^{75}$ The blood levels of methanol in the $26,000 \mathrm{mg} / \mathrm{m}^{3}$ group ranged from 8.34 to 9.26 $\mathrm{mg} / \mathrm{ml}$ after 1 day of exposure and from 4.84 to $6.00 \mathrm{mg} / \mathrm{ml}$ after 10 days of exposure.

The highest concentration of methanol produced slight maternal toxicity (unsteady gait) and a high incidence of congenital malformations, predominantly extra or rudimentary cervical ribs and urinary or cardiovascular defects. Among 15 litters exposed to $26,000 \mathrm{mg} / \mathrm{m}^{3}, 14$ contained at least 1 fetus with a skeletal malformation, and 10 contained at least 1 fetus with a visceral malformation. These incidences of malformation were significantly different from the control group $(p<0.05)$ which had no skeletal or visceral malformations in any of 15 litters. Similar malformations were seen in the group exposed to $13,000 \mathrm{mg} / \mathrm{m}^{3}$, but the incidences were not significantly different from those of controls. No increase in malformations was observed in the group exposed to $6500 \mathrm{mg} / \mathrm{m}^{3}$, which the authors interpret as a no-effects level for this test system.

It was noted when reviewing this study that different incidences of visceral malformations were reported in the text than were reported in the accompanying tables. Those inconsistencies should be resolved before accepting the reliability of this paper. Moreover, the occurrence of maternal toxicity in the significantly affected group compromises an interpretation of the teratogenic effects as being solely the result of in utero methanol exposure.

Infurna and Weiss examined early behavioral development in Long-Evans rats exposed prenatally to methanol. ${ }^{76}$ The study focused on suckling and nest-seeking behaviors of the neonates. Treatment consisted of treating pregnant rats with a drinking solution containing $2 \%$ (volume ratio) methanol; one group received this treatment during gestational days 15 through 17 , and a second group received the treatment during days 17 through 19. This treatment resulted in an average methanol consumption of $2.5 \mathrm{~g} / \mathrm{kg} /$ day; controls received normal water. Increased latency to suckling behavior was observed in pups from both groups of methanol-treated dams, when the pups were tested $24 \mathrm{~h}$ after birth. In addition, pups in both groups exposed prenatally to methanol displayed a lower efficiency in seeking and reaching their home area when tested on postnatal day 10. Methanol treatments did not affect litter size, birth weight, weight gain during the preweaning period, infant mor- tality, or day of eye opening. Also unaffected were duration of gestation, weight gain in the third week of gestation, and maternal behavior on the day of parturition. The authors conclude that methanol "can be defined as a behavioral teratogen in rats, since no other signs of toxicity were apparent either in the mothers or the offspring."

The behavioral effects noted in this study occur at tissue levels of methanol lower than those associated with teratoge. nesis in the study by Nelson et al. ${ }^{75}$ and may be of potential.: significance. However, maternal exposures to methanol during the 3-day treatment periods in the Infurna and Weiss study $(2.5 \mathrm{~g} / \mathrm{kg} /$ day $)$ are equivalent to at least 2500 daily human exposures to methanol vapors under expected worst-case conditions. (As discussed in Section IV of this paper, the added body burden of methanol resulting from worst-case exposure will be less than $1 \mathrm{mg} / \mathrm{kg}$.) Clearly, dose-effect data on the parameters studied by Infurna and Weiss would help clarify whether humans may experience similar effects at or near expected ambient exposure levels. Such studies may be of par-t. ticular value as they focus on endpoints representative of po. tentially subtle effects to the CNS.

\section{Dogs}

Sayers et al. exposed two dogs to about $13,000 \mathrm{mg} / \mathrm{m}^{3}$ methanol for about $3 \mathrm{~min}$ at hourly intervals eight times daily for 100 days, a total of 800 brief exposures. ${ }^{77}$ Both dogs were reported to have survived the exposure and exhibited no symptoms or unusual behavior or visual toxicity attributable to methanol poisoning. In an earlier study by Sayers et al. ${ }^{78}$ four dogs were exposed to airborne concentrations of methanol from 585 , to $650 \mathrm{mg} / \mathrm{m}^{3}, 8 \mathrm{~h} /$ day, 7 days/week for 379 days in a contin. uously ventilated chamber. The authors performed a wide range of hematologic determinations and ophthalmoscopic examinations. No adverse effects of any kind were reported.

\section{H. Prolonged Exposure to Non-Human Primates}

In a study of relevant concern, newborn stumptail macaques received aspartame in their formula daily for 9 months, starting; from between 17 and 42 days of age. ${ }^{79}$ Aspartame hydrolyzes: in the gut to aspartate, phenylalanine, and methanol. The methanol accounts for $10 \%$ of the molecular weight of aspartame; The exposed animals ate 1,2 , or 2.5 to 2.7 grams of aspary tame $/ \mathrm{kg} /$ day, which is the equivalent of 100,200 , and 250 to $270 \mathrm{mg}$ methanol/kg/day. The investigators report no effects with respect to growth, hematology, serum chemistry, urinalysis, and EEG patterns. The investigators concluded "Large" intakes of aspartame as part of the diet appear to have no effect upon developmental parameters of the infant macaque." This experiment, however, did not include histopathologic analysesis

These same animals also were subject to hearing tests and a battery of behavioral tests that included object discrimination pattern discrimination, and learning. ${ }^{80}$ Again, the investigator 


\section{Toxicology}

were unable to detect any effects from chronic aspartame ingestion. The test battery, according to the investigators, is one "that previously had been shown to be sensitive to age difference, size and locations of cortical lesions, form of early rearing history, some chronic dietary conditions, and exposure to varjous environmental toxins."

In a subchronic inhalation study, cynomolgus monkeys were exposed for 4 weeks ( $6 \mathrm{~h} /$ day, 5 days/week) to 650,2600 and $6500 \mathrm{mg} / \mathrm{m}^{3}$ of methanol vapor. ${ }^{70}$ The animals were observed twice daily for signs of toxicity, were given detailed physical examinations each week, and ophthalmoscopic examinations at pre-test and at termination. Following sacrifice, the animals' organs were examined and weighed, and selected tissues from all animals in the control and high exposure groups were examined microscopically. These included nasal turbinates, trachea, lungs, esophagus, liver, and the eye and optic nerve. No treatment-related effects on cynomolgus monkeys were observed in this study.

\section{Animal Studies Sponsored by New Energy Development Organization}

In Japan, the Institute for Applied Energy, with the sponsorship of the New Energy Development Organization (NEDO) conducted an extensive program in which rodents and nonhuman primates (cynomolgus monkeys) were exposed to methanol vapors. (In Japan, methanol has been contemplated as a fuel for power plants.) Non-human primates were exposed chronically for up to 30 months ( $22 \mathrm{~h} /$ day) to 13,130 , and $1300 \mathrm{mg} / \mathrm{m}^{3}$ of methanol vapors. Other groups of monkeys were exposed for shorter durations ( 6 days to 7 months) to a higher range of levels $\left(2300\right.$ to $\left.13,000 \mathrm{mg} / \mathrm{m}^{3}\right)$. Also, monkeys were subjected to metabolism evaluations during a 48-h period that followed intraperitoneal administration of methanol ( 25 to $3000 \mathrm{mg} / \mathrm{kg}$ ).

In the rodent experiments, rats (Fischer 344 ) and mice (B6C3Fl) were exposed to 13,130 , and $1300 \mathrm{mg} / \mathrm{m}^{3}$ of methanol for 12 months to examine for toxic effects unrelated to carcinogenesis, and for 24 months (rats) and 18 months (mice) to examine for tumor induction (all exposures were for $2 \mathrm{~h} /$ day). These same exposure levels were used in rat experiments (Sprague-Dawley) that tested for potential effects on reproductive performance over two generations. Teratology experiments also were carried out on Sprague-Dawley rats exposed to 0, 260, 1300 , and $6500 \mathrm{mg} / \mathrm{m}^{3}$ for days 7 to 17 of gestations. Finally, Fischer 344 rats were subjected to metabolic evaluations like those performed on the macaques.

The NEDO program also included a battery of genotoxic assays, with various cell and bacterial systems exposed to methanol. The summary report issued by NEDO in $1987,{ }^{81}$ and presented in part at scientific meetings, ${ }^{82}$ in general concludes that toxic, reproductive, and carcinogenic effects are not evitent at chronic exposure levels of $130 \mathrm{mg} / \mathrm{m}^{3}$, and teratologic ffects do not occur at $1300 \mathrm{mg} / \mathrm{m}^{3}$. However, the 1987 report does indicate the possibility of subtle effects in the CNS of non-human primates exposed chronically to $13 \mathrm{mg} / \mathrm{m}^{3}$, specifically, the appearance of "reactive astrocytes". These results may be of significance with regard to the exposure of the public to methanol vapors. The authors of the report attach little biological significance to these findings.

Unfortunately, the report does not include a sufficient amount of technical data and histopathological findings to enable a critical review of the experiments and their results. However, the types of experiments performed are crucial to the evaluation of potential risks from exposure to airborne substances. Perhaps further evaluation of the experimental methods of this program and data will help clarify the results observed and their relationship to methanol exposure.

\section{METABOLISM OF METHANOL AND MECHANISMS OF TOXICITY}

The nature of the dose-effect relationship for any substance is rooted in the mechanisms that govern the uptake of that substance and processing in the body. The better the understanding of those mechanisms, the greater one's ability to project the potential consequences that may result from an environmental exposure of a specific magnitude and time course. Furthermore, elucidating the physiological and biochemical pathways of action furthers the understanding of the determinants of interindividual variability and, therefore, of individual sensitivity.

This section describes the fate of inhaled methanol and its metabolites. Its objective is to provide a mechanistic and quantitative basis for methanol's acute toxic syndrome, such that one may assess the potential of anticipated ambient exposures (Section II) to initiate known toxic processes. The exposures of concern in this report, in all likelihood, result in methanol doses well below those that produce the acute effects discussed in the previous section. The literature on metabolism and toxic mechanisms, although concerned primarily with the clinical (i.e., mostly acute) aspects of poisoning, is nevertheless highly relevant to the objectives of this paper.

Unfortunately, there are no data with which to address directly the mechanisms that underlie the chronic effects of methanol. However, because the chronic effects on record (Section III) bear a qualitative similarity to the well-studied acute effects, one may adopt a "working" assumption that acute and chronic effects share, to some extent, common pathways of action. Of course, the possibility that chronic exposure induces effects by means presently unknown is one that must, by definition, remain open.

Section III described the early developments that led to the recognition of the non-human primate as an appropriate model for acute human methanol toxicity. Despite the unique qualities of non-human primates, there are many important character- 
istics of methanol uptake and metabolism that are common to all mammalian species, and these are covered first.

\section{A. Uptake and Distribution}

Regardless of its exposure route, methanol distributes readily and uniformly to all organs and tissues in direct relation to their water content. ${ }^{83}$ Methanol distribution throughout the body is, therefore, ubiquitous. Blood methanol concentration, a parameter used frequently in the literature to characterize the body burden of methanol, is, on the average, equal to $83 \%$ of its aqueous concentration. Urine, the other body fluid most commonly sampled, contains methanol concentrations 20 to $30 \%$ higher than blood..$^{83,84}$

The means of methanol distribution explains that all exposure routes - oral, percutaneous, intraperitoneal, and inhalation - are toxicologically equivalent. For ingestion and intraperitoneal administration, the initial body burden is simply the amount of methanol given divided by body weight.

For short-term inhalation, an upper-bound estimate of initial body burden assumes a total absorption of the inhaled vapor. this value is calculated as $\left(M_{v} \times V_{E} \times t\right) / B W ; M_{v}=$ vapor concentration, $V_{E}$ ventilation rate, $t=$ duration of exposure, BW $=$ body weight. In reality, the absorption of inhaled methanol is less than $100 \%$, with one reference reporting about $60 \% .^{52}$ An immediate application of this formula is to calculate the maximum initial body burden of methanol under an anticipated, worst-case, condition. Such a case might involve a 70 $\mathrm{kg}(\mathrm{BW})$ person, breathing at a rate of $20 \mathrm{~m}^{3} /$ day $\left(V_{E}\right)$ (i.e., roughly twice resting ventilation), exposed to $200 \mathrm{mg} / \mathrm{m}^{3}\left(\mathrm{M}_{\mathrm{v}}\right)$ methanol vapor for $15 \mathrm{~min}(\mathrm{t})$ in a personal garage hot-soak situation (no ventilation, disabled canister). For $100 \%$ absorption, the resulting body burden is $0.6 \mathrm{mg} / \mathrm{kg}^{*}$, which is at least 500 times lower than doses of acute clinical significance (i.e., greater than $0.3 \mathrm{~g} / \mathrm{kg}$ ). Table 6 lists the methanol body burdens that follow inhalation in several scenarios of interest and those that follow dietary intake of aspartame; the table also indicates the average background body burden of methanol.

\section{B. Clearance and Metabolic Kinetics}

Following uptake and distribution, methanol clears from the body. Clearance proceeds with half-times of 1 day or more for high doses (greater than $1 \mathrm{~g} / \mathrm{kg}$ ) and about $3 \mathrm{~h}$ for low doses (less than $0.1 \mathrm{~g} / \mathrm{kg}$ ). ${ }^{16.27 .84}$ Methanol is either excreted unchanged (direct excretion) in urine and exhaled breath, or it enters a metabolic pathway (in the liver), whose ultimate product is carbon dioxide. The metabolic process is of importance, because methanol acute toxic properties (Section III) are linked to intermediate metabolites, not to the alcohol itself.

*The value of $200 \mathrm{mg} / \mathrm{m}^{3}$ is the best current estimate for the worst-case condition in a personal garage. The higher figure $\left(650 \mathrm{mg} / \mathrm{m}^{3}\right)$ reported in one study was based on limited testing of a prototype vehicle. More recent studies indicate that methanol emissions from vehicles idling for $5 \mathrm{~min}$ in poorly ventilated garages are unlikely to exceed $200 \mathrm{mg} / \mathrm{m}^{3}$.

\section{Table 6}

Methanol Body Burden for Selected Situations

\begin{tabular}{|c|c|}
\hline Exposure scenario & Condition \\
\hline $\begin{array}{l}\text { Personal garage } \\
\text { "Hot-soak" }\end{array}$ & $\begin{array}{l}200 \mathrm{mg} / \mathrm{m}^{3}, 15 \mathrm{~min}, \\
\text { twice resting ventilation } \\
100 \mathrm{mg} / \mathrm{m}^{3}, 5 \mathrm{~min} \\
\text { twice resting ventilation } \\
100 \mathrm{mg} / \mathrm{m}^{3}, 5 \mathrm{~min}, \\
\text { resting ventilation }\end{array}$ \\
\hline $\begin{array}{l}\text { Self-service } \\
\text { refueling }\end{array}$ & $\begin{array}{l}50 \mathrm{mg} / \mathrm{m}^{3}, 4 \mathrm{~min}, \\
\text { twice resting ventilation }\end{array}$ \\
\hline 12-02 diet beverage & $555 \mathrm{mg}$ aspartame/1 \\
\hline $\begin{array}{l}\text { Dietary intake of } \\
\text { Aspartame (w/o } \\
\text { diet beverages) }\end{array}$ & Normal diet \\
\hline
\end{tabular}

Added body

burden of methanol

$0.6 \mathrm{mg} / \mathrm{kg}^{\circ}$

$0.1 \mathrm{mg} / \mathrm{kg}$

$0.03 \mathrm{mg} / \mathrm{kg}$

$0.04 \mathrm{mg} / \mathrm{kg}$

$0.3 \mathrm{mg} / \mathrm{kg}^{\mathrm{b}}$

$0.3-1.1 \mathrm{mg} / \mathrm{kg} / \mathrm{d}$

$0.5 \mathrm{mg} / \mathrm{kg}^{\mathrm{c}}$

a Assumes all inhaled methanol absorbed across respiratory epithelium; in ? all probability, less (approximately $60 \%$ of inhaled) is absorbed. ${ }^{32}$

- Assumes all aspartame-derived methanol crosses gut mucosa instantaneously; because of the time required for hydrolysis and transport, peaki measured levels reach $70-75 \%$ of the value in the table ${ }^{58}$.

c Based on value of $0.73 \mathrm{mg} / \mathrm{l}$ of blood. 52

The time course of the disappearance of methanol from the circulation reflects the combined action of both direct excretion and metabolism. A number of studies have been conducted in humans to examine for clearance of methanol from the cirs culation following low-level exposures.

Leaf and Zatman monitored methanol disappearance from the circulation of three human volunteers to whom 3,5 , and $7 \mathrm{ml}$ (or 2.4, 4.0, and $5.6 \mathrm{~g}$ ) of methanol were administered orally (highest dose, $0.08 \mathrm{~g} / \mathrm{kg}$ ).$^{84}$ Blood levels were reflected in urine samples collected every $2 \mathrm{~h}$ for at least $12 \mathrm{hr}$. The results were consistent for all subjects at all doses: methanoly disappearance obeyed first-order kinetics with a balf-time of about $3 \mathrm{~h}$ (i.e., every $3 \mathrm{~h}$, the concentration of methanol was halved).

Sedivec et al. exposed four volunteers for $8 \mathrm{~h}$ to methanol vapors at concentrations of 102,205 , and $300 \mathrm{mg} / \mathrm{m}^{3} .52$ They analyzed urine samples through the exposure period and for the $18 \mathrm{~h}$ that followed exposure. Urine levels of methanol were proportional to the vapor concentration throughout the obser vation period and, when exposure terminated, urinary methanol concentrations decreased exponentially with a half-life of roughly 2.5 to $3 \mathrm{~h}$.

Similar kinetics of methanol disappearance from blood were observed in human adults and infants to whom aspartame (10\%) methanol) was administered. ${ }^{57.58}$ The adult subjects received the equivalent of up to $20 \mathrm{mg} / \mathrm{kg}$ methanol and the infantsi 
received $10 \mathrm{mg} / \mathrm{kg}$. Therefore, the clearance of methanol from the human circulation after body burdens as high as $80 \mathrm{mg} / \mathrm{kg}$ are achieved follows first-order kinetics with a half-time $\left(T_{1 / 2}\right)$ of about 2.5 to $3 \mathrm{~h}$; the rate constant for total clearance, $k_{T}$, is therefore $0.693 / T_{1 / 2}$ or between 0.23 and $0.28 \mathrm{~h}^{-1}$.

Several studies have examined the percent of methanol that is excreted as $\mathrm{CO}_{2}$. This value reflects the fraction of the initial dose of methanol that clears by the metabolic route. The available data suggest that, following a low dose of methanol (2 $\mathrm{mg} / \mathrm{kg}$ ) to non-human primates (rhesus monkeys) and rats (CD1), as much as $90 \%$ is metabolized. ${ }^{85}$ Because methanol metabolism is a saturable process (see below), one expects its efficiency to decrease with larger doses. However, Eells et al. showed that even after a very high dose $(1 \mathrm{~g} / \mathrm{kg})$ of radiolabeled methanol to monkeys (species), $78 \%$ of the activity recovered within $24 \mathrm{~h}$ was as exhaled $\mathrm{CO}_{2} \cdot{ }^{86}$

\section{Mechanisms of Clearance}

The discussion that follows develops in greater detail the mechanisms that account for metabolism's dominant role in methanol clearance. This analysis will enable a sharper assessment of the potential for health effects under expected exposure conditions.

The observations that total clearance of methanol from body water proceeds with first-order kinetics at low doses (less than $0.1 \mathrm{~g} / \mathrm{kg}$ ) justifies the supposition that each separate pathway also obeys first-order kinetics and, thus, is characterized uniquely by its own rate constant. If such is the case, $\mathrm{k}_{\mathrm{T}}$, the rate constant for total clearance, equals the sum of rate constants for all pathways; furthermore, the fractional contribution of each pathway to clearance is equal to its rate constant divided by the sum of constants.

Each of the three major clearance pathways that were identified earlier may be assigned a rate constant: $k_{r}$ represents direct renal excretion of methanol; $k_{p}$ represents direct pulmonary excretion of methanol; and $k_{m}$ represents metabolic clearance. Expressed mathematically, the preceding states that, if all pathways obey first-order kinetics, then, $k_{T}=k_{f}+k_{p}$ $+k_{m}$, and that the fractional contribution of each pathway, e.g., metabolism, is $k_{m} / k_{T}$. These pathways are displayed schematically in Figure 1. The figure indicates with a dotted line that, in addition to $\mathrm{CO}_{2}$, the metabolic pathway generates for-

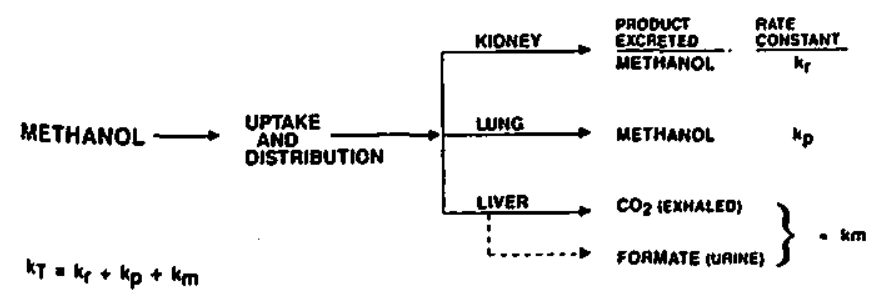

FGURE 1. Schematic diagram of clearance pathways for methanol following uptake and distribution throughout the body. mate, which is detectable in urine. Formate is the toxic metabolite apparently responsible for methanol's acute toxic syndrome in humans and primates. However, at the low doses of concern in this report, formate, as a metabolic end product, is excreted in quantities that are negligible compared to $\mathrm{CO}_{2}$. Thus, for the analysis presented in the discussion that follows, $\mathrm{CO}_{2}$ excretion represents the quantitative metabolism of methanol. The principles governing formate generation are explored in depth later in this section.

In the following analysis, rate constants for each pathway are derived on the basis of physiologic or kinetic principles, and, to test their validity, they are compared to empirical data.

\section{Direct Renal Excretion of Methanol}

The kidney apparently exerts no active control over the urinary concentration of methanol. Consequently, the methanol content of urine that enters the bladder maintains the aqueous concentration of methanol in the blood that entered the kidney. ${ }^{52.83,84}$ Thus, the rate at which methanol clears into the urine is directly proportional to its blood level, which satisfies the condition for first-order kinetics.

Under these conditions, $k_{r}$, the rate constant for direct renal excretion of methanol, equals the rate of urine formation divided by the total volume of body water. A "typical" $70-\mathrm{kg}$ person contains roughly 421 of water $(60 \%)$ and produces on the average $60 \mathrm{ml}$ of urine per hour $(0.86 \mathrm{ml} / \mathrm{h} / \mathrm{kg})$. Therefore, one may project a $\mathrm{k}_{\mathrm{r}}$ of $0.0014 \mathrm{~h}^{-1}$; half-time for this pathway is simply $0.693 / \mathrm{k}_{\mathrm{r}}$ ( 20 days). This simple formulation allows one to predict that renal processes account for $k_{r} / k_{T}$ of all the methanol cleared. Since $\mathrm{k}_{\mathrm{T}}$ was estimated earlier as 0.23 , the renal contribution to the total is about $0.6 \%$.

Leaf and Zatman measured urinary excretion of methanol from three human subjects after they ingested a dose of $3.2 \mathrm{~g}$ of methanol (av $0.05 \mathrm{~g} / \mathrm{kg}$ ). ${ }^{84}$ These investigators determined that at $12 \mathrm{~h}$ post-ingestion (when more than $90 \%$ of a methanol dose has cleared the circulation) an average of $0.76 \%$ of the initial dose was excreted in the urine. Jacobsen et al. studied renal clearance of methanol in a $65-\mathrm{kg}$ victim of methanol poisoning who was undergoing treatment, which included diuresis of 7.01 over a $24-h$ period, i.e., a urine production of $4.2 \mathrm{ml} / \mathrm{h} / \mathrm{kg}^{87}$ as mentioned earlier, urine formation in a "normal" 70-kg person proceeds at around $60 \mathrm{ml} / \mathrm{h}$, or $0.86 \mathrm{ml} / \mathrm{h} / \mathrm{kg}$. Renal clearance of methanol in the patient was measured as $5.7 \mathrm{ml} / \mathrm{min}(0.34 \mathrm{l} / \mathrm{h})$. (Clearance expressed in this manner has only a hypothetical meaning - it is as if each minute, $5.7 \mathrm{ml}$ of blood were totally cleared of methanol.) Assuming the patient had a body water content of $60 \%$, and a blood water content of $83 \%$, the calculated rate constant for renal clearance of methanol during diuresis is, $(0.34 \mathrm{l} / \mathrm{h} \times 0.83) /(65 \mathrm{~kg} \times$ $0.61 / \mathrm{kg})=0.007 \mathrm{~h}^{-1}$.

The value just calculated was obtained from the study of a patient treated with diuresis. To obtain a renal clearance constant $\left(k_{r}\right)$ for a person who is producing "normal" quantities 
of urine requires multiplying the clearance value just calculated by the ratio of "normal" urine production $(0.86 \mathrm{ml} / \mathrm{h} / \mathrm{kg})$ to urine production in the patient $(4.2 \mathrm{ml} / \mathrm{h} / \mathrm{kg})$, which yields a $k_{r}$ of $0.0014 \mathrm{~h}^{-1}$. On the basis of these data and calculations, the above estimate of $\mathrm{k}_{\mathrm{r}}$ seems reasonable.

\section{Direct Pulmonary Excretion of Methanol}

In the lung, a small fraction of blood-borne methanol diffuses passively from the pulmonary capillaries to the alveoli and is exhaled. The amount of methanol that crosses the blood-air barrier is directly proportional to its blood concentration, i.e., first-order kinetics, and is governed by its blood-air partition ratio; this parameter describes the relative content, at equilibrium, of a substance in each of two phases in contact.

For a first-order process, the rate of pulmonary excretion of methanol $=k_{p} \times$ blood methanol concentration. The rate constant, $k_{p}$, may be approximated by $V_{A} /(P R \times b w)$, where $\mathrm{V}_{\mathrm{A}}=$ alveolar ventilation, approximately $500 \mathrm{l} / \mathrm{h}$ during moderate activity for a typical $70-\mathrm{kg}$ person; bw $=$ body water, 42 I for same person; PR = methanol blood-air partition ratio, approximately $2000 .{ }^{88}$

Plugging in these values yields a value for $k_{p}$ of $0.006 h^{-1}$ (and therefore, a 5-day half-time). This derivation of the hypothetical value of $k_{p}$ is based, for purposes of simplification, on a constant alveolar ventilation. However, altering ventilation will affect the rate at which methanol is exhaled.

Jacobsen et al. also studied pulmonary excretion of methanol in the $65-\mathrm{kg}$ patient described previously. ${ }^{87}$ The patient, although admitted with methanol poisoning, was not hyperventilating. These investigators calculated a pulmonary clearance rate of $5.6 \mathrm{ml}$ of blood per minute $(0.34 \mathrm{l} / \mathrm{h})$ (i.e., each minute, $5.6 \mathrm{ml}$ of blood is hypothetically cleared totally of methanol). Assuming the patient had a body water content of $60 \%$ and a blood water content of $83 \%$, the calculated rate constant $\mathrm{k}_{\mathrm{p}}=$ $(0.34 \mathrm{1} / \mathrm{h} \times 0.83) /(65 \mathrm{~kg} \times 0.61 / \mathrm{kg})=0.007 \mathrm{~h}^{-1}$. This value and the theoretical estimate for $k_{p}\left(0.006 h^{-1}\right)$ are quite consistent.

\section{Metabolic Clearance}

In contrast to direct renal and pulmonary excretion, the metabolic conversion of methanol to carbon dioxide is not linear with concentration. In the 1960s, Tephly and colleagues demonstrated, in both rats (Holtzman) and rhesus monkeys, that in vivo metabolism of methanol to $\mathrm{CO}_{2}$ obeys Michaelis-Menten kinetics and, furthermore, that the metabolic kinetics for both species are very similar (Table 7) ${ }^{89,90}$ Briefly, this means that, with rising blood concentrations of methanol, the metabolic pathway demonstrates saturability and approaches a maximal conversion rate that it is unable to exceed. At saturation, the pathway demonstrates zero-order kinetics, which means the metabolic conversion rate is independent of concentration. However, at low concentrations (much lower than the Michaelis constant, $\mathrm{K}_{\mathrm{M}}$ ), processes that obey Michaelis-Menten kinetics behave as if they are first-order processes, with a rate

\section{Table 7 \\ "In Vivo" Michaelis-Menten Constants for the Metabollc Conversion of Methanol to $\mathrm{CO}_{2}$}

\author{
Species \\ Non-human primates 90 \\ (thesus monkeys) \\ Rats $^{89}$
}

$$
\begin{gathered}
V_{\max }(\mathrm{mg} / \mathrm{kg} / \mathrm{h}) \\
48 \\
30
\end{gathered}
$$
$\mathrm{K}_{\mathrm{m}}(\mathrm{mM})$
8.7
7.0

constant, $k_{m}$ of $V_{m x x} / K_{M}$. Subsequent time-course observations of methanol clearance from the blood of cynomolgus monkeys. given $2 \mathrm{~g} / \mathrm{kg}$ of methanol provide data that are consistent with those on rhesus monkeys shown in Table 7; specifically Noker. et al. recorded a zero-order clearance of about $50 \mathrm{mg} / \mathrm{kg} / \mathrm{h}$, and their graphic data display a transition from zero- to first. order kinetics at around $10 \mathrm{mmol}$ of methanol per liter of blood. 91

As estimated earlier in this section, a worst-case single exposure $\left(200 \mathrm{mg} / \mathrm{m}^{3}\right.$ methanol for $15 \mathrm{~min}$ ) produces a methanol body burden of less than $1 \mathrm{mg} / \mathrm{kg}$. For an individual with $60 \%$ body water, this upper level burden corresponds to $0.05 \mathrm{mmol}$ of methanol per liter (mM). This concentration is less than $1 \%$ of the $\mathrm{K}_{\mathrm{M}}$ for monkeys (roughly $10 \mathrm{mM}$ ), which reinforces the notion that, for environmental exposures of interest in this report, metabolism is operating in a first-order domain. To calculate $k_{m}$ requires transforming $V_{\max }$ into units of millimoles per hour. Makar et al. used ${ }^{14} \mathrm{C}$-labeled methanol (MW 34), and estimated body water of thesus monkeys at $70 \%$ of theirif weight. ${ }^{90}$ Thus, based on the values for rhesus monkeys in Table 7,

$$
\mathrm{k}_{\mathrm{m}}=\frac{\mathrm{V}_{\max }}{\mathrm{K}_{\mathrm{M}}}=\frac{1}{8.7} \times \frac{48}{(34)(0.7)}=0.23 \mathrm{~h}^{-1}
$$

The metabolic rate constant derived here is clearly much greater than the sum of constants for both direct renal $(0.0014$ $\left.\mathrm{h}^{-1}\right)$ and direct pulmonary $\left(0.0060 \mathrm{~h}^{-1}\right)$ excretion, which ex . $^{3}$ plains, from a kinetic viewpoint, why metabolism is expected to dominate the clearance of methanol from body water. As indicated earlier, this dominance has been confirmed in animal experiments.

Table 8 summarizes the preceding analyses and demonstrates that the clearance patterns of methanol observed empirically? are consistent with those one would project using basic phys iologic principles and Michaelis-Menten constants derived from studies of non-human primates.

\section{Toxic Mechanisms and Species Sensitivity}

The above discussion dealt with metabolism as if it prof ceeded as a "black-box" process with input (methanol) and 


\section{Table 8}

\section{Contribution of Renal, Pulmonary, and Metabolic Pathways to the Overall Clearance of Low Doses of Methanol $(<0.1 \mathrm{~g} / \mathrm{kg})$ : Comparison of Observed and Derlved Rate Constants}

\begin{tabular}{lccc}
\multicolumn{1}{c}{$\begin{array}{c}\text { Derived values } \\
\text { pathway }\end{array}$} & $\begin{array}{c}\text { Rate constant } \\
\text { k }\left(\mathrm{h}^{-1}\right)\end{array}$ & $\begin{array}{c}\text { Percent } \\
\text { clearance }\end{array}$ & Source \\
\cline { 2 - 4 } Direct renal & 0.0014 & 0.6 & Basic considerations \\
Direct pulmonary & 0.0060 & 2.5 & $\begin{array}{c}\text { Basic considerations } \\
\text { (partition ratio } \\
\text { from Reference 88) }\end{array}$ \\
Mctabolic & 0.23 & 96.9 & $\begin{array}{c}\text { Reference } 90 \\
\text { Total }\end{array}$ \\
& 0.24 & 100.0 &
\end{tabular}

\author{
Experimental/clinical observations \\ $0.76 \%$ of initial dose excreted in urine by $12 \mathrm{~h}$ \\ post-ingestion \\ $k_{\mathrm{r}}$ of $0.0014 \mathrm{~h}^{-1}$ for "normal" derived from \\ patient on diuresis \\ $k_{p}$ of $0.007 \mathrm{~h}^{-1}$ derived from patient data \\ $90 \%$ or more of dose excreted as $\mathrm{CO}_{2}$ \\ Half-time of approximately $2.5-3 \mathrm{~h}$ observed in \\ bumans, i.e., $\mathrm{k}_{\mathrm{r}}=0.23-0.28$
}

output $\left(\mathrm{CO}_{2}\right)$. This subsection probes the workings of that "black box", describes the biochemical events within the metabolic pathway that trigger methanol's toxic response, and discusses the major factors that influence species and individual susceptibility. The mechanisms discussed are associated directly with acute effects, as laboratory experiments and clinical analyses have amply demonstrated, but they probably contribute to chronic effects as well.

In the liver, the sequence of intermediate metabolites that lead from methanol to carbon dioxide is the same in all mammalian species studied: ${ }^{27}$

$$
\text { Methanol } \stackrel{1}{\rightarrow} \text { Formaldehyde } \stackrel{2}{\rightarrow} \underset{\left(+\mathbf{H}^{+}\right)}{\text {Formate }} \stackrel{3}{\rightarrow} \mathrm{CO}_{2}+\mathrm{H}_{2} \mathrm{O}
$$

Although the sequence of metabolites is identical for all species, there are interspecies differences with respect to the details of the reactions. Several of these differences bear directly on sensitivity to methanol and several appear not to. The details concerning methanol metabolism in both non-human primates and non-primates has been excellently reviewed elsewhere. ${ }^{27}$ The discussion that follows briefly reviews the entire metabolic process, but deals mainly with the aspects of metabolism related to toxicity.

The toxic properties of methanol, and the basis of species susceptibility, are rooted in the factors that govern the relative rates of formic acid (formate $+\mathrm{H}^{+}$) generation (steps 1 and 2) and formate oxidation to $\mathrm{CO}_{2}$ (step 3). In short, the toxic syndrome sets in if formate generation continues at a rate that exceeds its rate of removal; the latter is mainly a function of metabolism to $\mathrm{CO}_{2}$ since renal excretion of formate plays a minor role. This imbalance, if protracted, leads to an accumulation of formate coupled, eventually, to an uncompensated metabolic acidosis. The acidosis, if untreated, can prove lethal; however, even at physiologic $\mathrm{pH}$, formate is associated with ocular toxicity. Rats dispose of formate efficiently at any dose and thus escape toxicity, whereas, at sufficiently high doses, humans and non-human primates accumulate toxic metabolites and do not fare as well. The key to species differences lies in step 3 and, as explained below, it is directly related to the maximum rate at which the liver oxidizes formate.

\section{Step 1}

The first step in the metabolic sequence, in which methanol is oxidized to formaldehyde, reflects the major route of methanol clearance from the circulation (see previous discussion). In non-human primates, alcohol dehydrogenase mediates this initial step (rhesus monkeys); ${ }^{68}$ in rats (Holtzman and SpragueDawley), ${ }^{89.92}$ a catalase-peroxidative system is primarily responsible). Despite this difference, the initial metabolic step proceeds at similar rates in non-human primates and rats. ${ }^{27.89 .90}$ The values for $V_{\max }$ in Table 7 fairly well represent the maximal clearance rates observed in both species, although several studies in non-human primates have displayed even higher rates (up to $62 \mathrm{mg} / \mathrm{kg} / \mathrm{h}$ ). ${ }^{68.86 .91 .93}$ The rate at which methanol disappears from the circulation and enters its metabolic process is independent of "downstream" manipulations that either stimulate or slow the oxidation of formate (step 3).

\section{Step 2}

The second metabolic step converts formaldehyde to formic acid, which, in turn, dissociates to formate and a hydrogen ion. The step occurs as a two-reaction process, the second of which is irreversible. The first reaction, in which formaldehyde is oxidized to S-formylglutathione, requires reduced glutathione (GSH) and is mediated by an NAD-dependent formaldehyde dehydrogenase. In the second reaction, thiolase catalyzes the conversion of S-formylglutathione to formic acid. ${ }^{27}$ 
The nature of formaldehyde oxidation is important because formaldehyde itself is potentially toxic, and several "modern" references ascribe methanol ocular toxicity to it ${ }^{94.95}$ Formaldehyde has not, however, been detected in body fiuids or tissues following toxic methanol exposures. ${ }^{96.98}$ Furthermore, its clearance from the bloodstream following intravenous infusion occurs with a half-life of between 1 and $1 \frac{1}{2} \min$ and is followed by an immediate and corresponding rise in blood formate. ${ }^{98-100}$ The possibility that formaldehyde generated in the liver is active in the optic tract seems unlikely. Moreover, Martin-Amat et al. have demonstrated that formate alone given intravenously to rhesus monkeys induces the same ocular toxicity that is characteristic of methanol poisoning, with no sign of formaldehyde present. ${ }^{101}$

Thus, evidence supporting a role for formaldehyde in methanol toxicity is still lacking. The possibility that formaldehyde is generated locally in the retina or proximal optic nerve has not yet been ruled out and may merit some further attention. However, the present focus on formate as the principal toxic agent appears justified.

\section{Step 3}

In both non-human primates and rats, a folate-dependent pathway in the liver is responsible for the reactions that metabolize formate (step 3). Figure 2 shows the major aspects of this pathway. Formate first forms a complex with tetrahydrofolate (THF) that is sequentially converted to 10 -formyl-THF (by formyl-THF synthetase) and then to carbon dioxide (by formyl-THF dehydrogenase). THF is derived from folic acid in the diet and also regenerated in the folate pathway.

Although the folate pathway metabolizes formate in both species, rats use the pathway more efficiently, a fact that lies at the heart of species sensitivity to methanol. Both formate clearance from the blood and its metabolism to $\mathrm{CO}_{2}$ proceed about two to two and one-half times faster in rats than in nonhuman primates. For example, Clay et al. showed that, following its i.v. infusion at doses lower than $100 \mathrm{mg} / \mathrm{kg}(2.2$ $\mathrm{mmol} / \mathrm{kg}$ ), formate clears from rats with a half-time of $12 \mathrm{~min}$, and from non-human primates (pigtail macaque) with a halftime of $31 \mathrm{~min}$, and that the respective half-times decrease with increasing dosage in both species, which indicates that formate metabolism is a saturable process; ${ }^{67}$ these findings are consistent with previous research. ${ }^{102,103}$ Specifically, in the study by Clay et al. ${ }^{67}$ half-times in pigtail monkeys were 51 min at $470 \mathrm{mg} / \mathrm{kg}, 49 \mathrm{~min}$ at $285 \mathrm{mg} / \mathrm{kg}, 46 \mathrm{~min}$ at $200 \mathrm{mg} / \mathrm{kg}$, and $31 \mathrm{~min}$ at both 72 and $50 \mathrm{mg} / \mathrm{kg}$; at $670 \mathrm{mg} / \mathrm{kg}$, formate half-time in rats was $23 \mathrm{~min}$. However, following high doses of methanol $(4 \mathrm{~g} / \mathrm{kg}$ in pigtail monkeys, $6 \mathrm{~g} / \mathrm{kg}$ in SpragueDawley rats), formate accumulates appreciably only in monkeys, with only a subtle increase seen in rats (Figure 3). On the basis of relative metabolic efficiencies, one may have expected rats to accumulate 40 to $50 \%$ of the formate measured in non-human primates.

The apparent reason why rats do not accumulate formate

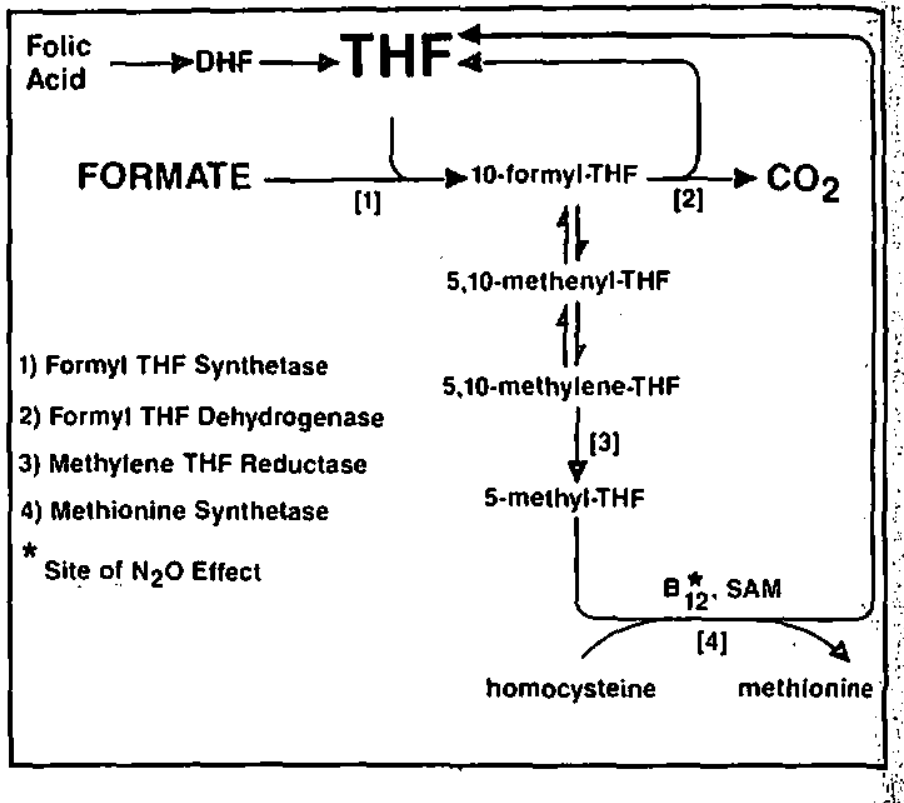

FIGURE 2. Metabolism of formate by folate-dependent reactions. DHF, dihydrofolic acid; THF, tetrahydrofolic acid; SAM, S-adenosylmethionine Reaction 1 is catalyzed by formyl-THF synthetase and requires prior activation of formate with ATP. Reaction 2 involves $\left[{ }^{10} \mathrm{~N}\right]$ formyl-THF dehydrogenase and utilizes NADP as a hydrogen acceptor. Reaction 3 is catalyzed by $5,10^{\circ}$ methylene-THF reductase and is essentially irreversible. Reaction 4 is cata: lyzed by 5 -methyl-THF homocysteine methyltransferase (methionine synthe - i (ase) and requires catalytic amounts of vitamin $B_{12}$ and SAM. (From Eells, wh J. T., Maker, A. B., Noker, P. E., and Tephly, T. R., Methanol poisoning and formate oxidation in nitrous oxide treated rats, J. Pharmacol. Exp. Ther, 217, 57, 1981. (With permission.)

noticeably at any dose of methanol is that the maximal rate of formate oxidation in rats $(1.6 \mathrm{mmo} / \mathrm{kg} / \mathrm{h})$ exceeds the maximal rate that steps 1 and 2 supply substrate $(30 \mathrm{mg} / \mathrm{kg} / \mathrm{h}$, equivalent to $0.9 \mathrm{mmol} / \mathrm{kg} / \mathrm{h}$, from Table 7). On the other hand, in non human primates, the "upstream" processes are able, with high enough methanol concentrations, to feed formate to the folate pathway at a rate $(1.4$ to $1.8 \mathrm{mmol} / \mathrm{kg} / \mathrm{h})$ that exceeds the metabolic capacity of the pathway $(0.75 \mathrm{mmol} / \mathrm{kg} / \mathrm{h})$. The "spillover" accumulates in the circulation which, if protracted, leads to the toxic consequences of methanol poisoning. These relationships are shown in Figure 4. At low doses of methanol, the process that clears methanol from the bloodstream and generates formate (3-h half-time) is considerably less efficiegit than the process that clears formate $(0.5-\mathrm{h}$ half-time in priy mates). Therefore, at low methanol exposures, formate is noty expected to accumulate to any major degree. Baumann and Angerer report that 20 workers exposed to an average of 140 $\mathrm{mg} / \mathrm{m}^{3}$ methanol for an 8-h work day registered an increased blood formate of $0.1 \mathrm{mM}$ at the end of their work-shift (back ground for humans ranges from 0.07 to $0.4 \mathrm{mM}$ - see Section III). ${ }^{48}$ Urinary excretion of formate, although detectable fol lowing both human and animal methanol exposures, plays minor role relative to metabolism in the overall clearance of formate. 


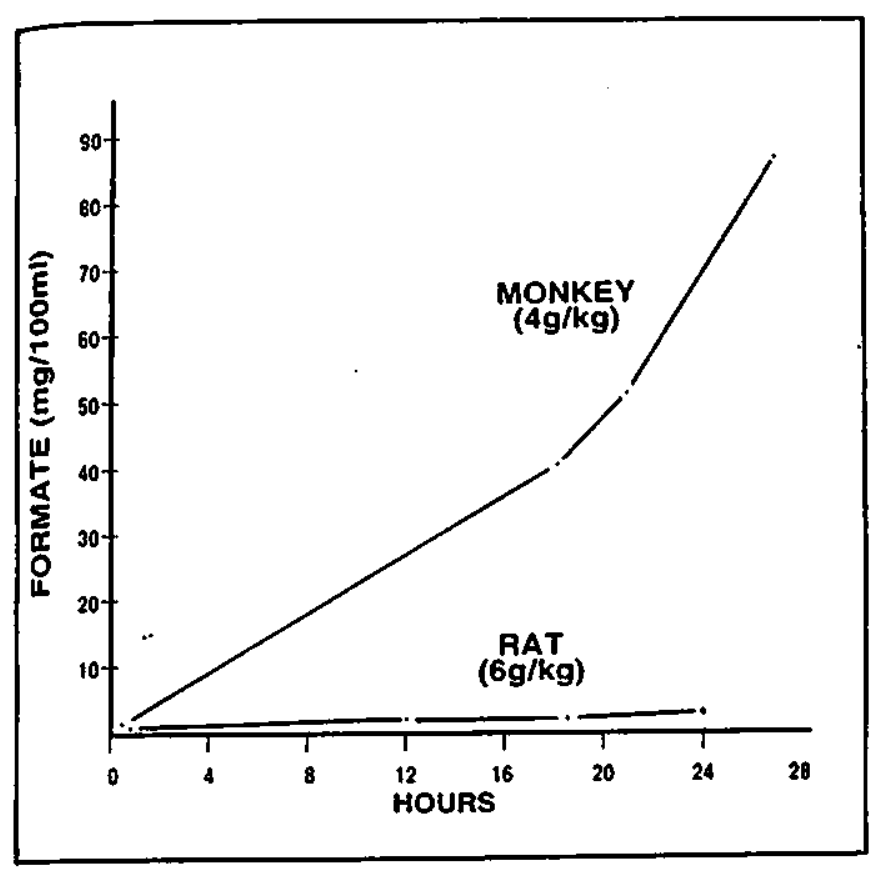

FIGURE 3. Blood formate concentrations in the monkey and rat after administration of methanol. Methanol was administered as a $25 \%$ solution in saline to the monkey $(4 \mathrm{~g} / \mathrm{kg}, \mathrm{i} . \mathrm{p}$.) and the rat $(6 \mathrm{~g} / \mathrm{kg}, \mathrm{i} . \mathrm{p}$.). Blood specimens were drawn at the indicated times after methanol administration. (From Clay, $K$. L., Murphy, R. C., and Watkins, W. D., Experimental methanol toxicity in the primates: analysis of metabolic acidosis, Toxicol. Appl. Pharmacol., 34, 49. 1975. With permission.)

The efficiency of formate metabolism is linked strongly to the hepatic concentration of THF, the molecule that initially complexes with formate. The factors, in turn, that control THF levels involve both the dietary level of folate and the dynamic equilibrium within the biochemical loop that regenerates THF (Figure 4).

In the 1970s, Tephly and colleagues studied the effects of dietary folate on species susceptibility to methanol toxicity. Makar and Tephly fed rats (Sprague-Dawley) a folate deficient diet and observed that these subjects suffer the effects of a methanol dose $(4 \mathrm{~g} / \mathrm{kg}$ ) that such animals ordinarily tolerate well when maintained on a control diet. ${ }^{104}$ (The folatedeficient period, although not specified by Makar and Tephly, was probably similar to the 6- to 8-week period used by Palese and Tephly. ${ }^{105}$ ) Specifically, folate-deficient rats become acidotic and accumulate formate (but not formaldehyde) in the same manner observed previously in non-human primates. The key to methanol toxicity in folate-deficient rats is a diminished capacity to oxidize formate. ${ }^{96.104}$ On the other hand, cynomolgus monkeys treated with folate or a folate derivative (5-formyl-THF), and given $2 \mathrm{~g} / \mathrm{kg}$ of methanol, maintained normal blood $\mathrm{pH}$ associated with only a modest rise in blood formate; in formate and became temporarily acidotic. As one would expect, folate-deficient monkeys displayed even greater susceptibility to methanol than their normally fed counter-

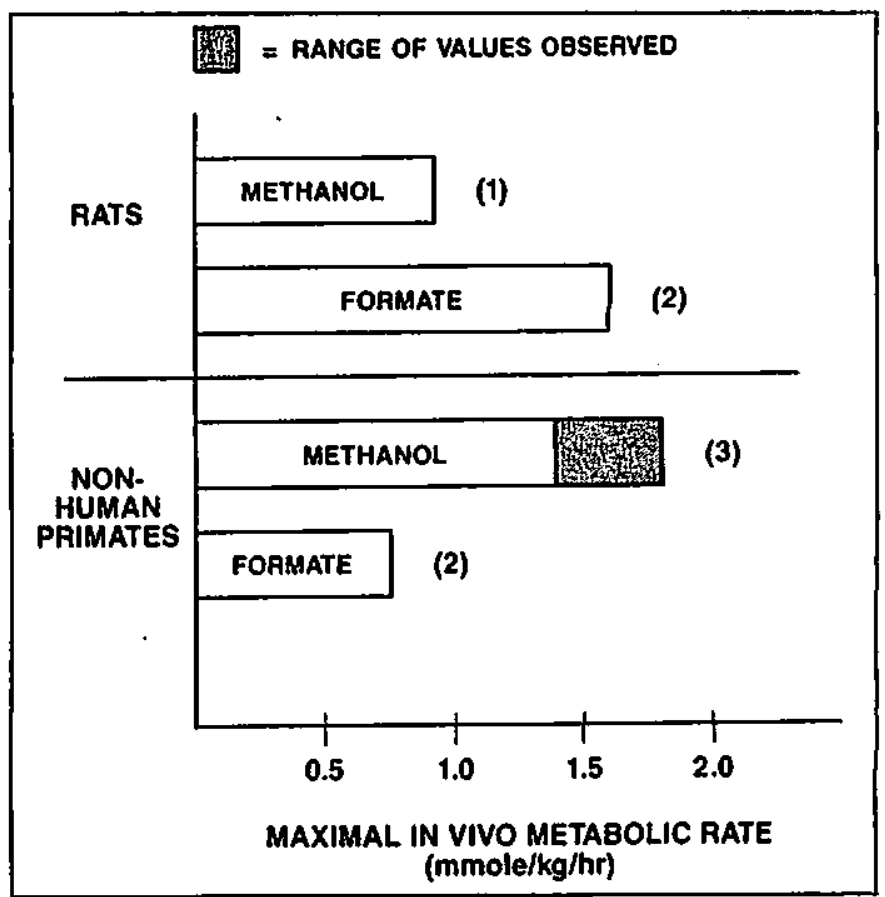

FIGURE 4. Maximal in vivo metabolic rates for methanol and formate in the rat and non-human primate $(\mathrm{mmol} / \mathrm{kg} / \mathrm{h}$ ) (dotted lines indicate range observed). ([1] from Reference 89; [2] from Reference 106; [3] from References $68,86,90$, and 91 .)

parts. ${ }^{106}$ In all of these cases, the effect of dietary folate on formate metabolism was the direct link to altered sensitivity to methanol; slowing formate metabolism induced a methanol-sensitive state.

The dependence of formate oxidation on endogenous folate regeneration has been demonstrated in both rats and non-human primates. Using both species, Eells and colleagues performed a series of experiments in which the folate feedback loop was opened pharmacologically and the animals then were challenged with either formate or methanol. ${ }^{86,107,108}$ The agent used to poison the loop was nitrous oxide $\left(\mathrm{N}_{2} \mathrm{O}\right)$, an anesthetic gas, which, among its actions, blocks methionine synthetase (Figure 2 , Step 4), by inactivating vitamin $B_{12}$, the enzymes cofactor. Nitrous oxide treatment slowed formate metabolism and heightened methanol sensitivity. With $\mathrm{N}_{2} \mathrm{O}$, rats (Sprague-Dawley) given $4 \mathrm{~g} / \mathrm{kg}$ methanol and monkeys (cynomolgus) given 1 $\mathrm{g} / \mathrm{kg}$ became acidotic, but animals given methanol without $\mathrm{N}_{2} \mathrm{O}$ maintained normal blood $\mathrm{pH}$.

Eells et al. showed further, using Sprague-Dawley rats, that the critical variable in these experiments was the concentration of hepatic THF. ${ }^{108}$ The concentration of total hepatic folate remained unaffected by $\mathrm{N}_{2} \mathrm{O}$ treatment. The extent to which $\mathrm{N}_{2} \mathrm{O}$ slowed formate oxidation was linked directly to the extent that $\mathrm{N}_{2} \mathrm{O}$ decreased hepatic levels of THF. When plotted against each other, formate oxidation and hepatic THF correlated very closely $(r=0.89)$. Nitrous oxide thus acts to upset the dynamic 
equilibrium of the folate regenerative pathway so as to increase methylated and formylated folates at the expense of THF.

Subsequent research has focused on the comparative aspects of folate biochemistry among rats, monkeys, and humans. Black et al. studied rats (Sprague-Dawley) and non-human primates (cynomolgus monkeys) and compared the levels of folate intermediates and the activities of folate-dependent enzymes in the livers of both species. ${ }^{109}$ Although total folate content of the two was practically identical, the THF concentration in monkey livers was $59 \%$ of the value in rats. This lower level of THF in non-human primates is consistent with their heightened sensitivity to methanol, and the ratio of THF levels in the two species is similar to the ratio of their maximal rates of formate oxidation $(47 \%)$. The authors describe several species differences in folate-dependent enzyme activities that may contribute to different states of dynamic equilibrium in the folate regenerative pathway, whereby the species-specific balance of THF to total folate favors the rat's natural resistance to methanol. The authors note that the equivalence of total folate in both species "suggests that monkeys do not have a deficit in the dietary or hepatic uptake of folates, as compared to rats."

More recently, Johlin et al. reported that human levels of total hepatic folate and THF were 62 and 57\%, respectively, of the levels in rat liver, and they were 26 and $15 \%$, respectively, of the levels in mouse liver. ${ }^{110}$ These authors also noted that the ratio of formate oxidation rate to THF level was equivalent for humans, rats, and mice. They also observed that the enzyme responsible for the final step in the oxidation of formate to $\mathrm{CO}_{2}$ is reduced in both human and non-human primate liver. Research is continuing to unravel the intricacies of the folate pathway and its relationship with methanol toxicity.

\section{E. Sequence of Acute Toxicity: Acidosis and Ocular Toxicity}

The establishment and refinement of the non-human primate model has enabled researchers to both characterize carefully the sequence of events that follow large single doses of methanol and to propose mechanisms of action. Figure 5 (from Tephly) illustrates the time course for several key blood pasameters that follows a lethal $(3 \mathrm{~g} / \mathrm{kg})$ dose of methanol. "' As shown, in the symptomless latent period, formate accumulates and homeostatic mechanisms compensate for the increasing acid load. Between 12 and $16 \mathrm{~h}$ post-ingestion, homeostatic reserve is exhausted, and the animal enters an acidosis from which it does not recover. Through the latter phase, the blood level of formate (and perhaps of other organic ions such as lactate) continues to increase. With lower doses $(0.5$ and 2.0 $\mathrm{g} / \mathrm{kg}$ ), formate and acid start to accumulate, but, with a continuously diminishing supply of methanol in the bloodstream, the critical blood parameters (formate, $\mathrm{pH}$ ) revert to normal values (Figure 6). Presumably, at these lower doses, the initial steps that oxidize methanol generate formate in the excess of the formate-metabolizing capacity of the folate pathway. How-

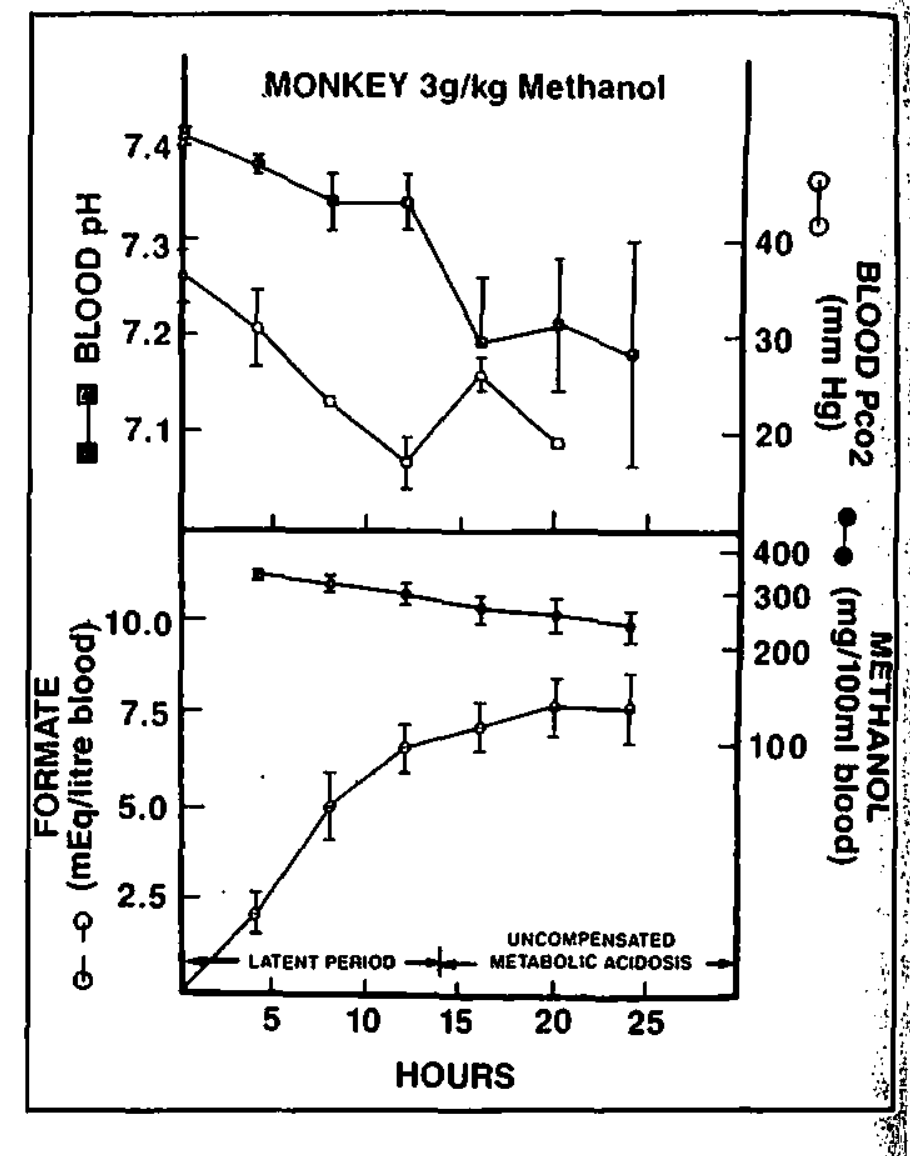

FIGURE 5. Metabolic acidosis, formate accumulation, and methanol metabolism in the monkey. Each point represents the mean \pm SEM of at least three animals. (From Tephly, T. R., Introduction: factors in responses to this environment, Fed. Proc., 36, 1627, 1977. With permission.)

ever, as methanol clearance continues, and its blood concenti tration drops, the rate of formate generation drops below the capacity of the folate pathway, which allows both the through put of formate and the excess blood formate to be metabolized and results in a return to normal. For lethal doses, formate generation continues in excess of the formate-metabolizing caje pacity into the terminal state.

Non-human primates and humans that survive the lethal ef fects of methanol are still at considerable risk of developin' damage to the visual system. In 1977, Martin-Amat et al introduced a non-human primate model (rhesus monkeys) fo sustaining methanol toxicity at a sublethal level to allow ful expression of the ocular toxicity to develop; ${ }^{101}$ acidosis an elevated formate in blood (and cerebrospinal fluid [CSF]) chat acterized this sustained toxic period. Using this model, Hayre et al. noted ophthalmoscopic changes, consisting primarily $\delta$ hyperemia and edema of the optic disc, between 43 and 17 . $\mathrm{h}$ from the start of ingestion. 112 Except for some engorgemei of the retinal veins in the later phase of edema, the reting vasculature remained normal throughout the observation $p$ 

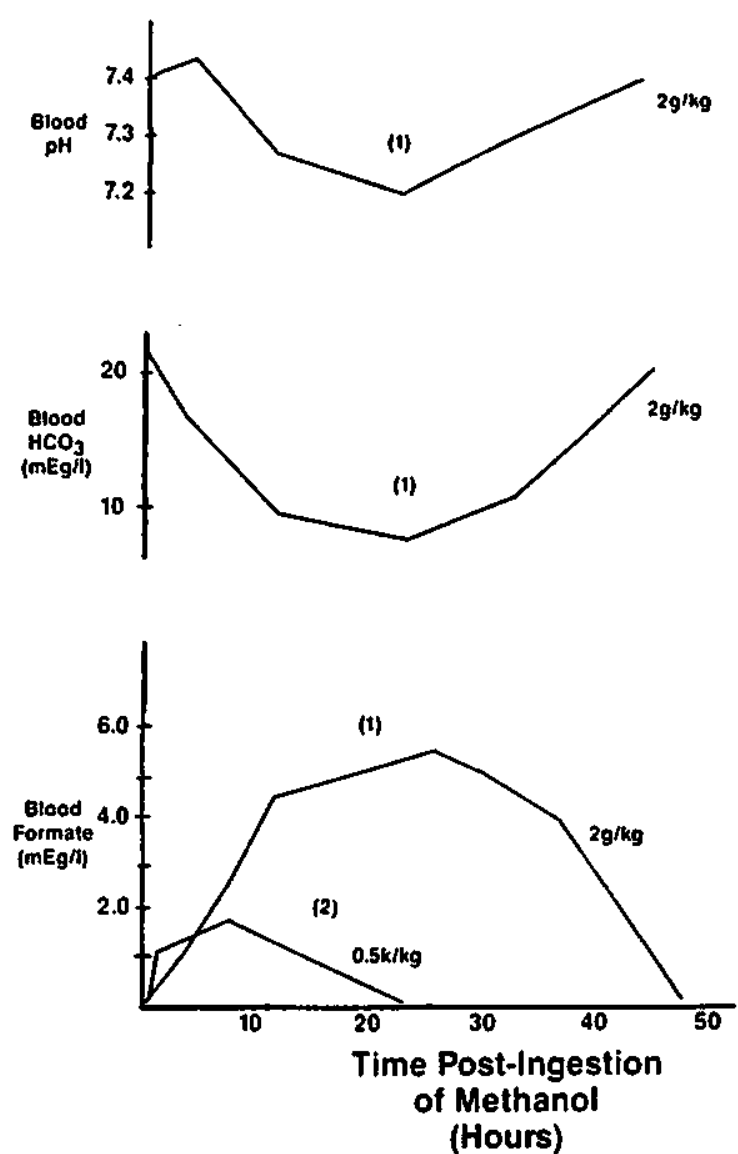

FIGURE 6. Blood levels of bicarbonate and formate and blood pH following oral administration of methanol to cynomolgus monkeys. ${ }^{91.106}$

riod. Optic disk edema was the only sign of angiographic abnormality in the entire retina. In addition, the monkeys' pupils were dilated and unresponsive to light, as with human intoxication.

Baumbach et al. further explored the injury to the visual system using light and electron microscopic examinations of tissue from the same animals that Hayreh et al. studied. ${ }^{113}$ According to their observations, the primary sites of injury are the optic nerve head and the intraorbital portion of the optic nerve (i.e., the site where the retinal nerve fibers converge and become a nerve bundle); the retina itself is undisturbed. They state,

\footnotetext{
The morphological alterations seen in the optic nerve and optic nerve head in methyl alcohol-poisoned thesus monkeys car be separated into two categories - alterations within axons and alterations of glial cells. Alterations seen in axons include mitochondrial swelling and clustering, neurotubular dissuption, the formation of vesicles, and increased density of amorphous protcins, and axonal enlargement. Glial cell alterations include astrocytic swelling and swelling of the oligodendroglial cytoplasm in contact with the optic nerve axon.
}

The precise mechanisms of this injury are not yet clear, but several investigators have suggested a sequence that involves the interaction of formate-induced metabolic inhibition with the observed compression and swelling of optic nerve fibers. The initiating event is believed to involve the action of formate as a metabolic poison, specifically as an inhibitor of cytochrome oxidase. This protein is located in the mitochondria and is the last in a chain of cytochromes and other molecules that transfer electrons sequentially to molecular oxygen. In so doing, they generate adenosine triphosphate (ATP), the basic molecular form of energy of the cell. Formate inhibits cytochrome oxidase with a $\mathrm{K}_{\mathrm{i}}$ (the concentration that achieves $50 \%$ cytochrome inhibition) of between 5 and $30 \mathrm{mM}$, which overlaps the range of formate concentrations observed in acute methanol intoxication both experimentally and clinically. ${ }^{114.115}$ Furthermore, as $\mathrm{pH}$ decreases, inhibition increases, which sug. gests that the active species is undissociated formic acid (described further below).

The myelin sheath (or white matter) of the optic nerve is comprised of cells that normally have low reserves of cytochrome oxidase due to their low metabolic requirement, and thus it may be particularly sensitive to formate-induced metabolic inhibition. At the point where the optic nerve bundle forms, formate has access to the nerve from both the choroid circulation behind the retina and from the CSF. (Martin-Amat et al. observed formate accumulation in the CSF of rhesus monkeys given large methanol doses; ${ }^{101}$ the CSF formate levels were similar to those in the blood.) If sufficiently damaged from metabolic inhibition, the cells of the white matter (oligodendroglial cells) may swell and, in essence, form small "cuffs" around individual nerve fibers, which themselves may then exhibit a compression-type injury in the form of swelling and edema proximal to the cuff in the optic nerve head. Such compression on the fiber will slow the transport of proteins, neurotubules, and mitochondria from the cell body of the fiber (located in the retina - the retinal ganglion cell) to the fiber axoplasm, which renders the fiber increasingly deficient in essentials and, thus, susceptible to formate-induced injury. Once the nerve fiber is no longer able to sustain the metabolic energy to conduct electrical impulses, visual decrements will occur. This schema for the progression of toxic events is consistent with the morphological evidence presented by Hayreh et al. ${ }^{112}$ and Baumbach et al., who used the non-human primate model for methanol-induced ocular toxicity.

The onset of acidosis may serve to accelerate the sequence just described. As mentioned, the inhibition of cytochrome oxidase increases with decreasing $\mathrm{pH}$, which suggests that undissociated formic acid is the active inhibitor of cytochrome oxidase. The Henderson-Hasselbalch equation predicts that with a $\mathrm{pH}$ drop of 0.3 , which is commonly observed in methanol poisoning, the concentration of undissociated formic acid $\left(\mathrm{pK}_{\mathrm{a}}\right.$ 3.8) doubles. Thus, acidosis may potentiate the biochemical inhibition of celiular respiration and speed the onset of cellular injury. Also, the acidosis as it progresses will begin to induce 
circulatory failure, which leads to tissue hypoxia and lactate production, both of which further increase the acid load, increasing undissociated formic acid, etc. This cycle, termed "circulus hypoxicus" by Jacobsen and McMartin, ${ }^{28}$ may hasten the end stage consequences of methanol poisoning. While acidosis may accelerate formate toxicity, Martin-Amat et al. showed that, even at physiologic $\mathrm{pH}$, formate is capable of inducing the same ocular toxicity in non-human primates (rhesus monkeys) as is observed in methanol poisoning. ${ }^{116}$ Formate maintained between 12 and $34 \mathrm{mEq} / 1$ (equivalent to millimolar) in the blood for 25 to $50 \mathrm{~h}$ inhibited the pupillary response and caused optic disc edema.

\section{F. Accumulation of Formate in Humans: High and Low Doses}

Large increases in circulating formate are linked firmly to the acute toxic manifestations that result from large doses of methanol (approximately $0.3 \mathrm{~g} / \mathrm{kg}$ and above). As discussed earlier in this section, one would expect a sharp increase in formate accumulation to occur with saturation of the folate pathway, which metabolizes formate. Applying formulas and values used previously in this report, and assuming that nonhuman primates adequately model humans, one may calculate the approximate dose of methanol that achieves this saturation. Assume (1) the maximal rate of methanol metabolism $\left(\mathrm{V}_{\max }\right)$ in humans is equivalent to the value given in Table 7 for nonhuman primates, $48 \mathrm{mg}{ }^{14} \mathrm{C}$-methanol $/ \mathrm{kg} / \mathrm{h}$ (or $2.0 \mathrm{mM} / \mathrm{h}$, if the subject consists of $70 \%$ water); (2) the maximal rate of formate oxidation is the same for both species, $35 \mathrm{mg}{ }^{14} \mathrm{C}$ formate $/ \mathrm{kg} / \mathrm{h}$ or $1.1 \mathrm{mM} / \mathrm{h}$; (3) the Michaelis constant for methanol metabolism in humans is the same as in non-human primates, $8.7 \mathrm{mM}$; and (4) formate is relatively evenly distributed through body water, a reasonable assumption based on the determination by Jacobsen et al. of the volume of formate distribution $(0.5 \mathrm{l} / \mathrm{kg}){ }^{87}$ Then using the Michaelis-Menten equation, one can estimate the concentration (or dose) of methanol, $M$, that puts the folate pathway into saturation, as follows:

$$
\begin{aligned}
1.1 & =2.0 \times \frac{M}{8.7 \pm M} ; \\
M & =\begin{array}{l}
11 \mathrm{mM} \text { or } 210 \mathrm{mg} / \mathrm{kg}, \text { for a person } \\
\text { with } 60 \% \text { body water }
\end{array}
\end{aligned}
$$

The calculated value of $M$, although only a crude estimate, is not far from the low end of the range of methanol doses considered potentially significant clinically $(0.3 \mathrm{~g} / \mathrm{kg})$. For reference to the situations of concem in this report, a $210-\mathrm{mg} / \mathrm{kg}$ body burden of methanol would be achieved if a $70-\mathrm{kg}$ person breathing at $20 \mathrm{~m}^{3} /$ day (twice resting) was exposed for $1 \mathrm{~h}$ to roughly $18,000 \mathrm{mg} / \mathrm{m}^{3}$, absorbing $100 \%$ of the material inhaled. Since worst-case conditions for single exposures present about $200 \mathrm{mg} / \mathrm{m}^{3}$ for the period spent in a hot-soak garage (15 min or less), the likelihood of overwhelming the folate pathwial in such situations seems remote. The same conclusion also 0 would probably apply to attendants in filling stations, who may be exposed to $50 \mathrm{mg} / \mathrm{m}^{3}$ of methanol vapors for minutes at time, many times a day.

Nevertheless, low-level exposures to methanol do cause smal increases in blood and urine formate levels. Baumann and Angerer measured formate in $\mathbf{2 0}$ workers in a printing offic 6 who were exposed to an estimated methanol concentration 0 \% between 111 and $174 \mathrm{mg} / \mathrm{m}^{3}$ of methanol throughout the wort day. ${ }^{48}$ Over the course of 1 day, the blood level of format rose an average of $4.7 \mathrm{mg} / 1(3.2 \mathrm{mg} / 1$ before the work shift to $7.9 \mathrm{mg} / \mathrm{l}$, when work ended), and urinary formate rose ant average of $7.1 \mathrm{mg} / 1$ (13.1 to 20.2), both increases statistically/ significant. Every worker registered an increase for both pa rameters. A control group maintained relatively stable levels through the day $(5.3 \mathrm{mg} / \mathrm{l}$ blood; $11.8 \mathrm{mg} / \mathrm{l}$ urine). Heinrich and Angerer performed a similar study in a chemical plant measuring methanol (blood and urine) and urinary formate ing 20 workers exposed throughout the work day to $120 \mathrm{mg} / \mathrm{m}^{3}$ methanol vapor, geometric mean (range of 48 to $300 \mathrm{mg} / \mathrm{m}^{3}$ ). 4 . At the end of the day, blood and urine methanol in workerst were 8.9 and $21.8 \mathrm{mg} / \mathrm{l}$, respectively; a control group registere留 a mean blood value of $<0.6 \mathrm{mg} / \mathrm{l}$ and a mean value in urine of $1.1 \mathrm{mg} /$. Urinary formic acid was significantly higher in the workers $(17.2 \mathrm{mg} / \mathrm{l})$ than in the controls $(12.7 \mathrm{mg} / \mathrm{l})$.

Stegink et al. assayed formate in the blood and urine of six adults who were given $200 \mathrm{mg} / \mathrm{kg}$ aspartame, equivalent to 20 $\mathrm{mg} / \mathrm{kg}$ methanol..$^{58}$ Blood methanol peaked at $26 \mathrm{mg} / \mathrm{l}$, but i increase in blood formate was detectable over a preexposif value of $19.1 \mathrm{mg} / \mathrm{l}$. Urinary formate increased in the 0 - to and the 4- to 8-h post-ingestion periods to 2.9 and 2.4 time the preexposure levels (expressed as micrograms of form per milligrams of creatinine); after the 8-h post-ingestion $\mathrm{p}$ riod, urinary formate was at background levels. In addition ophthalmologic examinations conducted $25 \mathrm{~h}$ post-ingestio were all normal. These studies present a wide variability in th background levels of blood formate. The source of the differt ences has not been identified, but may relate to the method used to assay for blood formate and, possibly, to dietary other lifestyle or ethnic differences between the occupationally exposed populations in West Germany, ${ }^{48}$ and the adults studid in the U.S. 58

These studies demonstrate that methanol exposures that of not challenge the metabolic limits of the folate pathway, nong theless, do generate small amounts of formate in blood an urine. In the Baumann and Angerer study, ${ }^{48}$ workers weet exposed to about $140 \mathrm{mg} / \mathrm{m}^{3}$ of methanol for $8 \mathrm{~h}$, assumin $20 \mathrm{~m}^{3} /$ day ventilation and $100 \%$ absorption, the dose to a $7 \%$ $\mathrm{kg}$ person would be $13 \mathrm{mg} / \mathrm{kg}$. According to Sedivec et al absorption might be as low as $60 \%, 32$ which would lower the estimate to perhaps $8 \mathrm{mg} / \mathrm{kg}$. These investigators noted the blood formate increased from 3.2 to $7.9 \mathrm{mg} / \mathrm{l}$ over the court 


\section{Toxicology}

of the work day. In the aspartame study of Stegink et al., ${ }^{38}$ the dose was higher $(20 \mathrm{mg} / \mathrm{kg})$, but the high background level of blood formate (19.1 $\mathrm{mg} / \mathrm{l}$ preexposure) may have masked any subtle increases that the aspartame may have caused. Urinary formate rose in all three studies, which indicated that, following any low-level exposures to methanol ( 8 to $20 \mathrm{mg} / \mathrm{kg}$ ), small quantities of formate probably are generated as well; but unless the methanol is labeled in some distinct way, incremental formate may not be discriminated from background. In worst-case single exposure conditions of concern here (see above), it is doubtful whether an added body burden of $1 \mathrm{mg} / \mathrm{kg}$ or less of methanol will, once metabolized, impose measurably on background levels of formate.

Although incremental formate from ambient methanol exposures may not be measurable against background levels, sufficient data on methanol and formate kinetics are available to project estimates of formate accumulation following a single brief exposure to methanol vapor. The Appendix to this paper presents a two-compartment model in which the entire inhaled dose of methanol enters the metabolic pathway and is converted to formate with a rate constant, $k_{c}$, reflective of blood clearance, and formate is metabolized to $\mathrm{CO}_{2}$ with a rate constant of $k_{f}$. An example in the Appendix models formate accumulation in an individual whose $T_{1 / 2}$ for methanol clearance is $3 \mathrm{~h}$, and whose $T_{1 / 2}$ for formate metabolism is $\mathbf{4 5} \mathrm{min}$ (approximately the value measured by Malomy in humans given formate orally). ${ }^{117}$ For such a person, an initial body burden of $1 \mathrm{mg}$ methanol per kilogram that results from a worst-case exposure generates, in the model, a peak formate level of $0.0082 \mathrm{mM}$ (aqueous) at $2.0 \mathrm{~h}$ postexposure (see Appendix Figure 1). Because background formate is about $0.2 \mathrm{mM}$, the incremental contribution from methanol exposure is about 4\%. For more realistic exposures, the model predicts considerably lower levels of methanol-derived formate. Finally, the example shows the sensitivity of formate accumulation to the efficiency of formate metabolism (Appendix Table 1). In short, decreased efficiency raises the peak formate concentration, as expected.

Although the model is only hypothetical, it is consistent with Stegink et al.'s inability to detect incremental blood formate levels following a $200 \mathrm{mg} / \mathrm{kg}$ dose of aspartame (equivalent to $20 \mathrm{mg} / \mathrm{kg}$ methanol). ${ }^{58}$ Because $1 \mathrm{mg} / \mathrm{kg}$ methanol projects for the subject in the above example to a peak of $0.0082 \mathrm{mM}$ (aqueous) formate, $20 \mathrm{mg} / \mathrm{kg}$ would project proportionally to $0.16 \mathrm{mM}$ or $7.4 \mathrm{mg} / \mathrm{l}$; in terms of blood concentration, this peak value (assuming relatively even distribution of formate in body water) corrects to $6.1 \mathrm{mg} / \mathrm{l}$. In Stegink et al.'s subjects, the preexposure blood formate level averaged $19.1 \mathrm{mg} / \mathrm{l}$, roughly 3 times greater, and, in addition, displayed considerable variability around the mean. Thus, it is not surprising that a relatively small and transient peak of blood formate, with its own inter-individual variability, was not detected in this study.

\section{CONCLUSION}

\section{A. Discussion}

Methanol has been long recognized for its acute toxicity in humans, most frequently in association with ingestion of methanol- or wood alcolol-tainted beverages. The literature is replete with case histories of methanol poisoning, and its syndrome is well-characterized. Acute effects appear after a symptomless latent period of approximately 1 day and consist of an acidosis with a superimposed ocular toxicity. Methanol intoxication may lead to blindness and is potentially lethal. Susceptibility among individuals to the acute effects of methanol is highly variable, but $300 \mathrm{mg} / \mathrm{kg}$ is considered to be at the low end of the dose range considered lethal. Variability may be associated with concurrent ingestion of ethanol, which slows the progression of methanol toxicity, or with dietary status, which may play a role in susceptibility.

The recognition in the 1950 s of the non-human primate as a model of human intoxication spurred research efforts that have produced a vastly improved understanding of methanol's toxic mechanisms. Methanol toxicity is primarily attributable to its metabolite, formate, which participates in the processes that lead to acidosis and visual disturbances. Methanol itself, unless taken in narcotic doses, is not considered the toxic principal in acute poisoning. In non-human primates, ocular effects are associated with blood formate concentrations in excess of 5 to $10 \mathrm{mM}$ and require 1 day or more to express themselves morphologically. ${ }^{101.116}$ A methodical examination of potential effects in the visual system from lower levels of formate is lacking.

The dose-effect relationships for the chronic effects of methanol in humans are not well described. On the basis of clinical case reports and a small number of epidemiologic studies, it appears that prolonged exposures to levels above the ACGIH TLV $\left(260 \mathrm{mg} / \mathrm{m}^{3}\right)$ may produce effects akin to the symptoms described for acute toxicity, but less severe. These include headache and blurred vision. Acute and chronic effects may, to some extent, share common pathways of action.

The data base for animals exposed chronically to methanol is very limited, especially in non-human primates. In one chronic feeding study, infant stumptail macaques ingested up to $2.7 \mathrm{~g}$ aspartame $/ \mathrm{kg} / \mathrm{d}$, i.e., $270 \mathrm{mg}$ methanol $/ \mathrm{kg} / \mathrm{d}$, for 9 months with no physiologic or behavioral effects observed ${ }^{81.82}$ Histopathologic analyses were not included in these studies.

Cynomolgus monkeys exposed subchronically $(6 \mathrm{~h} / \mathrm{day}, 5$ days/week for 4 weeks) to methanol vapors at concentration levels of 650,2600 , and $6500 \mathrm{mg} / \mathrm{m}^{3}$ displayed no signs of toxicity either during the exposure period or at post-exposure necropsy. ${ }^{70}$ The latter included histologic analyses of several tissues, including conducting airways and lung, liver, kidney, and those tissues associated with the visual system. NEDO sponsored studies in which cynomolgus monkeys were exposed for up to 30 months to 13,130 , and $1300 \mathrm{mg} / \mathrm{m}^{3}$. As discussed 
in Section III, the summary report issued by NEDO indicates potential chronic effects in the CNS at the lowest exposure level, but the details supplied in the report are insufficient to enable a critical review of the study, and further evaluation may be necessary.

Although non-primates do not serve as adequate models for the acute toxic syndrome, they may serve as subjects that can be used to explore the effects of methanol that are unrelated to its metabolism (i.e., direct effects). So far, the data are limited and do not reveal a firm indication that effects would result from repeated human exposures under anticipated conditions (see Section III):

A study of Sprague-Dawley rats exposed for 4 weeks to methanol vapors $\left(650,2600\right.$, and $\left.6500 \mathrm{mg} / \mathrm{m}^{3}\right)$ reports no exposure-related effects, except for increased discharges around the nose and eyes. ${ }^{70}$ Cynomolgus monkeys exposed to the identical regimen showed no such effects. ${ }^{70}$ In light of the latter observation, the biological significance of the increased discharges in rats is uncertain. In a behavioral teratology study, Infurna and Weiss report decrements in suckling and homing - behaviors of rat pups (Long-Evans) born to mothers that had received methanol in their drinking water for 3 days during the third week of pregnancy. ${ }^{76}$ The maternal dose level was 2.5 $\mathrm{g} / \mathrm{kg} /$ day, a level at least three orders of magnitude higher than the doses that will occur during expected worst-case exposures. Because of the absence of data on these behavioral endpoints at dose levels relevant to expected exposure conditions, the observations of this study remain interesting, but of limited value. Finally, as part of the large-scale research program sponsored by the NEDO, ${ }^{81}$ rats and mice were subjected to longterm exposures to methanol $\left(13,130\right.$, and $\left.1300 \mathrm{mg} / \mathrm{m}^{3}\right)$ to examine for toxicologic, as well as carcinogenic, effects (see Section III). The summary report issued by NEDO indicates that rodents do not experience effects at $130 \mathrm{mg} / \mathrm{m}^{3}$. However, as mentioned in the discussion of these studies in Section III, the results have not yet been published with sufficient detail to allow for critical review.

As indicated, single worst-case exposures will produce methanol body burdens of less than $1 \mathrm{mg} / \mathrm{kg}$. Specifically, a $70-\mathrm{kg}$ person breathing at a rate of $20 \mathrm{~m}^{3} /$ day exposed to $200 \mathrm{mg} / \mathrm{m}^{3}$ of methanol for $15 \mathrm{~min}$ (i.e., hot-soak, worst case exposure), absorbing $100 \%$ of the inhaled vapor, receives a dose of 0.6 $\mathrm{mg} / \mathrm{kg}$ (for $60 \%$ body water, this is an aqueous concentration of $0.03 \mathrm{mM}$ ). More realistically, a $5-\mathrm{min}$ exposure to $50 \mathrm{mg} / \mathrm{m}^{3}$ while refueling at the same ventilation, results in $0.05 \mathrm{mg} / \mathrm{kg}$, or $0.003 \mathrm{mM}$. Background blood concentrations of methanol are about $0.75 \mathrm{mg} / \mathrm{l}$ or, correcting for the water content in blood (83\%), about $0.9 \mathrm{mg} / \mathrm{ml}$, or $0.03 \mathrm{mM}$ aqueous concentration. Thus, for worst-case single exposures, the inhaled body burden of methanol will be equivalent to its preexisting background level, but for more realistic exposures, it will be perhaps 10 times less. For comparison, aspartame in the diet is expected to produce additional methanol burdens that average between
0.3 and $1.1 \mathrm{mg}$ methanol $/ \mathrm{kg} /$ day (exclusive of carbonated ber erages), and a single $12-0 z$ beverage will contribute about 20 $\mathrm{mg}$, or $0.3 \mathrm{mg} / \mathrm{kg}$, for a $70-\mathrm{kg}$ person. ${ }^{35}$

The more important issue focuses on the generation of for mate and its potential toxicity. As indicated in the report ambient exposures will not come near to challenging the for mate metabolizing capacity of the folate pathway and, there. fore, formate will not accumulate to frankly toxic levels. In one experiment, in which adults were given $200 \mathrm{mg}$ aspar tame $/ \mathrm{kg}$ orally $(20 \mathrm{mg}$ methanol $/ \mathrm{kg}$ ), increased formate was undetectable in blood against a background of $19.1 \mathrm{mg} /(0.4$ $\mathrm{m} M) .{ }^{\mathrm{sB}}$ Urinary formate, however, increased about 2.5 -fold in the 8-h post-ingestion period. In a second study, workers in as printing office who were exposed for the 8-h work day to a mean $140 \mathrm{mg} / \mathrm{m}^{3}$ methanol vapor registered an increased blood formate of $4.7 \mathrm{mg} / \mathrm{l}(0.1 \mathrm{mM})$ at the end of the day against $\mathrm{a}$ preexposure level of $3.2 \mathrm{mg} / \mathrm{l}$ (the levels in unexposed controls was $5.3 \mathrm{mg} / \mathrm{l}$ ); urinary formate increased as well. ${ }^{48}$ The relas tively lower background in the latter study allowed the detect tion of the increased formate in blood. For such low-level methanol exposures, the increase of formate detectable in blood and urine reflect normally operating pathways of methanoli: metabolism.

As discussed in Section IV, total methanol exposure in these studies exceeds, by almost an order of magnitude, any single exposure expected from automotive or refueling vapors. The data from these studies combined with hypothetical modelin calculations suggest that single worst-case ambient exposures i.e., 15 -min exposure to $200 \mathrm{mg} / \mathrm{m}^{3}$ at twice resting ventilation will, in a normal person, produce a temporary rise in bloo formate of negligible magnitude (4\%) compared to backgroun levels. Exposures in traffic situations (Table 2), assuming $100 \%$ fleet penetration, will produce even less.

Therefore, if methanol were to produce health effects normal subjects at or near the exposure levels (time and con centration) of concern, such effects would likely not be attrib utable to the generation of formate. Susceptibility to methano derived formate remains unknown among people with dietar or metabolic deficiencies (e.g., conditions affecting the level of liver folate or vitamin $B_{12}$ ), and remains unknown, as well li $_{\text {, }}$ as a function of age. However, if formate is not active toxi cologically and effects appear, an alternate mode of action (e.g., direct action of the alcohol) would need to be invest gated.

The exposures of immediate concern will occur daily, bu they will be brief and intermittent. If chronic exposures equivalent concentrations do not produce health effects, one? confidence that anticipated conditions present no health hazar would certainly be enhanced. However, a firm conclusion re garding chronic exposure cannot yet be drawn. To this point no human occupational studies have reported effects linked chronic methanol exposures below the TLV $\left(260 \mathrm{mg} / \mathrm{m}^{3}\right) .0$ the other hand, careful investigations of people exposed 
Iower levels have not been conducted, but would probably be very useful.

An analysis of the available peer-reviewed literature produces no evidence upon which to base a conclusion that exposure to low levels of methanol vapors will result in adverse health effects. This conclusion applies only to exposures that will occur as a result of the normal use of methanol as a vehicular fuel and not to exposures that may occur from ingesting methanol fuels or from spillage.

\section{B. Outstanding Research Issues}

The analysis presented in this paper indicates that adverse effects are not expected as a result of exposure to methanol emissions from motor vehicles. Nevertheless, should methanol become widely implemented as a motor vehicle fuel, billions of gallons per year of this substance would be introduced into the fuel marketplace. With such large-scale usage, exposure to methanol emissions, although resulting in very low doses, is likely to be very widespread. Given this enormous scale, it is important to identify research issues and opportunities that, if addressed with focused research, would further reduce the level of uncertainty about health effects.

Much of the research to date has focused on the toxicity of methanol that follows large acute doses taken orally and on refining clinical intervention strategies to treat that toxicity. Considerably less attention has been directed toward studying the effects that might occur following low-level chronic inhalation and the mechanisms that might be responsible. This paper has reviewed the few studies concerned with low-level exposure, and has attempted to glean from the high-exposure studies the evidence that can be applied to low-dose issues. Nonetheless, gaps in our knowledge about the biological effects of methanol remain, and bridging them would provide the public with increased confidence in methanol technology.

At present, the worldwide level of effort in addressing the health effects of methanol is quite small and could be expanded to tackle specific research issues. The following discussion identifies six research opportunities that, if undertaken, would contribute valuable information on the potential health effects of methanol. These research areas are not listed in priority order. In addition to evidence gathered from new research projects, important information may also be acquired from a re-analysis of the NEDO study on non-human primates and from unpublished data that may be available from studies conducted on the effects of aspartame that may be related to methanol.

The specific research opportunities are

1. Investigate dose-effect and time-course relationships between formate levels in blood and effects to the visual system. According to current knowledge, the toxicity to the visual system in methanol poisoning is attributable to the generation and accumulation of circulating for- mate. However, the blood fornate, in such cases, achieves levels much higher than those that will arise from environmental exposures of the public to vehicular methanol vapors. Thus, research is recommended that will define the relationship between the concentration and duration of formate in the blood and the signs of toxicity to the visual system.

2. Investigate local metabolism in the eye or optic nerve to determine if formaldehyde or formate is generated locally. As indicated in the report, formaldehyde is not believed to be responsible for the known toxic effects of methanol. Methanol metabolites, formaldehyde and formic acid, are generated mainly in the liver, and, at high enough doses, formate circulates to produce toxicity in the visual tract. One remaining uncertainty, though, is whether metabolic systems are present in retinal or optic nerve tissues that also may generate toxic metabolites locally. The presence of such systems could have implications for evaluating the potential consequences of chronic, low-level exposure.

3. Study potential susceptibility to low levels of methanol among people with dietary folate deficiency (or other suspect conditions) and within various age groups. The report concludes, "if methanol produces health effects in normal subjects at or near the exposure levels of concern, such effects would likely not be attributable to the generation of formate." One of the major implications of this statement is that a similar definitive conclusion cannot be drawn for individuals who may be susceptible to the effects of methanol. Furthermore, the Clean Air Act is written to ensure that potentially sensitive individuals remain protected. Thus, a potentially important research activity is to identify candidate determinants of susceptibility and to develop strategies to study their role in modulating susceptibility within the population. To this end, the use of animal models may be appropriate.

4. Conduct in-depth epidemiology study of workers exposed to methanol vapors. As discussed in the report, studies have been conducted on various occupational cohorts exposed to methanol vapors that have measured blood and urine levels of methanol and formate. However, health-related parameters were not included in the design of these surveys. Methanol is used widely enough in various industries such that exposure information can be collected on selected cohort and combined with data from health records, clinical examinations, and questionnaires to determine the extent to which chronic exposure to methanol affects workers, it at all.

5. Conduct chronic animal experiments. The most comprehensive animal research program undertaken to date was the one funded by NEDO. The report (Section III) indicates some of the difficulty understanding fully the findings that emerged from that program, particularly 
with reference to low-level chronic effects in non-human primates. A further difficulty arises with the design of that study. Specifically, chronic exposures in the study occurred at methanol levels of 13,130 , and $1300 \mathrm{mg} / \mathrm{m}^{3}$. Even if a no-observed-effects-level of $130 \mathrm{mg} / \mathrm{m}^{3}$ in this experiment (as the report suggests) is validated, uncertainty still persists about the possibility of effects occurring at levels somewhere between 130 and $1300 \mathrm{mg} / \mathrm{m}^{3}$, a range that includes exposure levels that may occur in several scenarios covered in Section II. Thus, a chronic study conducted with an appropriate animal model using well-chosen exposure levels and engaging a full quality control and peer-review process would constitute a valuable contribution.

6. Conduct dose-effect studies that address behavioral teratology. As discussed, exposure of gravid rats to a single high dose of methanol produced behavioral decrements in pups tested in the early post-natal period. Unfortunately, data are lacking that describe the relationship between the level of maternal exposure to methanol and the behavioral performance of the offspring. Thus, research to fill this gap in the database is recommended.

\section{APPENDIX KINETIC MODEL OF FORMATE ACCUMULATION FOLLOWING ACUTE METHANOL EXPOSURE}

The following two-compartment model may be used to estimate blood formate levels following brief (less than $15 \mathrm{~min}$ ), low-level exposures to methanol. Since blood clearance of methanol proceeds with about a 3-h half-time, such brief exposures can be considered as a single acute dose. The model assumes:

1. All metabolic pathways remain in a first-order domain.

2. Formate distributes relatively evenly to body water, and renal excretion of formate is negligible compared to metabolism.

3. The entire dose of methanol enters the metabolic pathway.

Consider the following system:

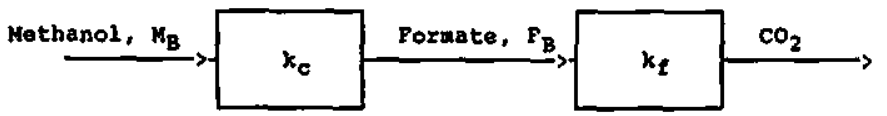

Let $t=$ time post-ingestion (hours); $M_{B}=$ aqueous concentration of blood methanol ( $\mathrm{m} M$, i.e., millimoles per liter) and, $\mathbf{M}_{\mathrm{B}}=\mathrm{M}_{\mathrm{Bo}}$ at $\mathrm{t}=0 ; \mathrm{F}_{\mathrm{B}}=$ aqueous concentration of blood formate $(\mathrm{m} M) ; \mathrm{k}_{\mathrm{c}}=$ clearance rate constant of methanol into the metabolic pathway; $k_{f}=$ rate constant of formate metabolism.
Then, using first-order principles,

$$
\frac{\mathrm{dF}_{\mathrm{B}}}{\mathrm{dt}}=\frac{-\mathrm{dM}_{\mathrm{B}}}{\mathrm{dt}}-\mathrm{k}_{\mathrm{f}} \mathrm{F}_{\mathrm{B}}
$$

and since

$$
\begin{aligned}
M_{B} & =M_{B_{0}} e^{-k_{c t}} \\
\frac{d M_{B}}{d t} & =-k_{c} M_{B_{0}} e^{-k_{c} t}
\end{aligned}
$$

Therefore

$$
\frac{d F_{B}}{d t}+k_{f} F_{B}=k_{c} M_{B o} e^{-k_{c} t}
$$

Multiplying both sides by $\mathrm{e}^{\mathrm{k}_{\mathrm{f}} \mathrm{yields}}$

$$
e^{k_{f}} \frac{d F_{B}}{d t}+k_{f} F_{B} e^{k_{f} t}=k_{c} M_{B D} e^{\left(k_{f}-k_{c}\right) t}
$$

or

$$
\frac{d\left(F_{B} e^{k_{f} t}\right)}{d t}=k_{c} M_{B o} e^{\left(k_{f}-k_{c}\right) t}
$$

Integrating and setting $F_{B}=0$ at $t=0$ yields

$$
F_{B}=\frac{k_{c}}{k_{f}-k_{c}} M_{B o}\left(e^{-k_{c} t}-e^{-k_{f} t}\right)
$$

and, setting $\mathrm{dF}_{\mathrm{B}} / \mathrm{dt}$ equal to zero solves for the time, $t_{\max }$, which $F_{B}$ is maximized,

$$
t_{\max }=\frac{\ln \left(k_{c} / k_{f}\right)}{k_{c}-k_{f}}
$$

Finally, the ratio of the maximized concentration of formate to the initial concentration of methanol is

$$
\frac{\left(F_{B}\right)_{\max }}{M_{B o}}=\frac{k_{c}}{k_{f}-k_{c}}\left(e^{-q}-e^{-s}\right)
$$

where

$$
q=\frac{k_{c}}{k_{c}-k_{f}} \ln \left(k_{c} / k_{f}\right)
$$

and

$$
r=\frac{k_{f}{ }^{\prime}}{k_{c}-k_{f}} \ln \left(k_{d} / k_{f}\right)
$$


This value depends only on the ratio of $k_{c}$ to $k_{c}$ (as does the "dimensionless time" $k_{c} t_{\max }$ ).

Thus, one may easily project blood formate levels using measured values of $k_{c}$ and $k_{f}$, as in the following example:

A worst-case exposure in a hot-soak garage produces a methanol body burden of $1 \mathrm{mg} / \mathrm{kg}$, which is equivalent to $0.05 \mathrm{~m} M$ $\left(\mathrm{M}_{\mathrm{Bo}}\right)$. Methanol clears from the bloodstream into the metabolic pathway with a $T_{1 / 2}$ of $3 \mathrm{~h}$, meaning $k_{c}=0.693 / 3=$ $0.23 \mathrm{~h}^{-1}$, and formate clearance proceeds with a $T_{1 / 2}$ of $45 \mathrm{~min}$ or $\mathrm{k}_{\mathrm{f}}=0.92 \mathrm{~h}^{-1}$.

Applying formulas (7) and (8) yields $t_{\max }=2.0 \mathrm{~h}$, at which lime $\mathrm{F}_{\mathrm{Bmax}}=0.0082 \mathrm{mM}$. Since measured levels of background formate are about $0.2 \mathrm{mM}$, the maximal increment of formate amounts to $4 \%$ of background.

For the example described, Appendix Figure 1 displays the time courses that Equations 2 and 7 predict for methanol and formate, respectively. Using the clearance characteristics of the example as a point of reference, Appendix Table 1 (center box is reference) shows the relative values of $t_{\max }$ and $F_{B}$ as $T_{1 / 2}$ for methanol and formate vary. The table shows the expected: as the efficiency of formate metabolism decreases relative to methanol clearance, formate accumulates to a greater

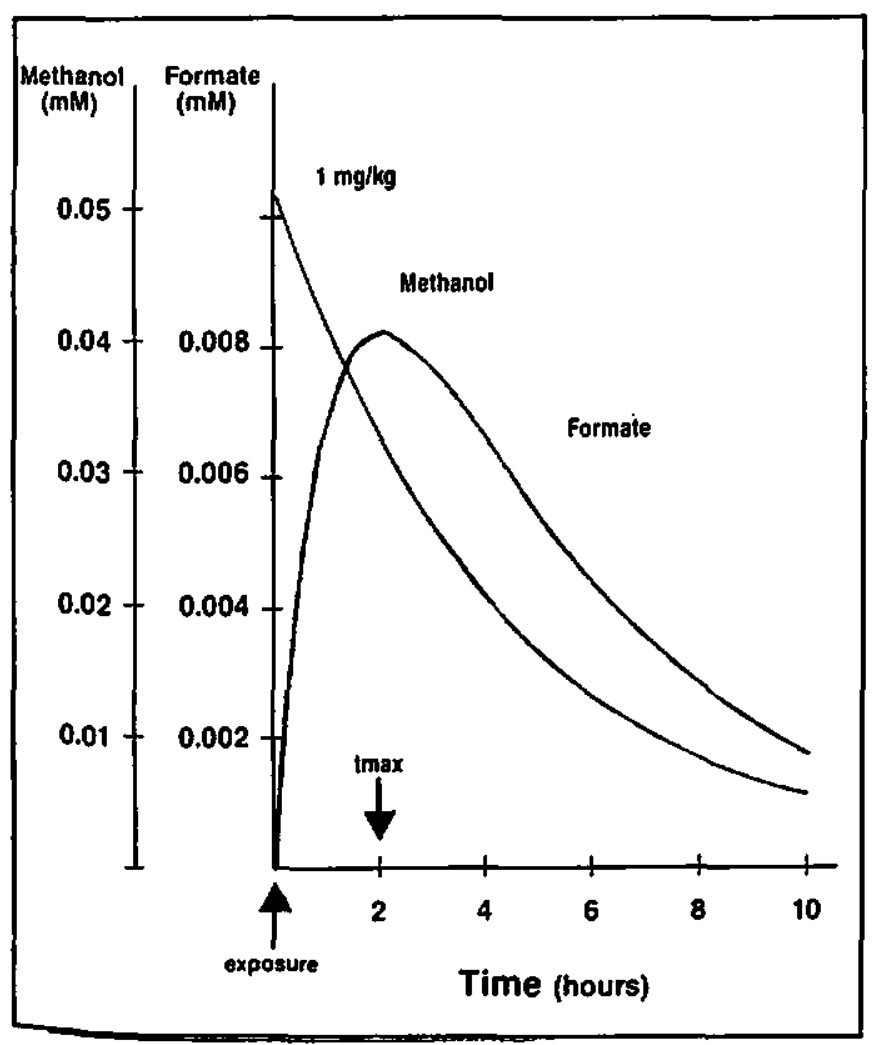

APPENDIX FIGURE 1. Blood levels of methanol and formate following an initjal body burden of I mg/kg methanol according to the two-compartment model presented in the text of the Appendix. Clearance half-times are $3 \mathrm{~h}$ for methanol and 45 min for formate.
Appendix Table 1

Relative Values of (1) Peak Blood Formate Level and (2) the Time from Methanol Exposure to Achleve that Level as a Function of the Blood Clearance Half-Times for Methanol and Formate

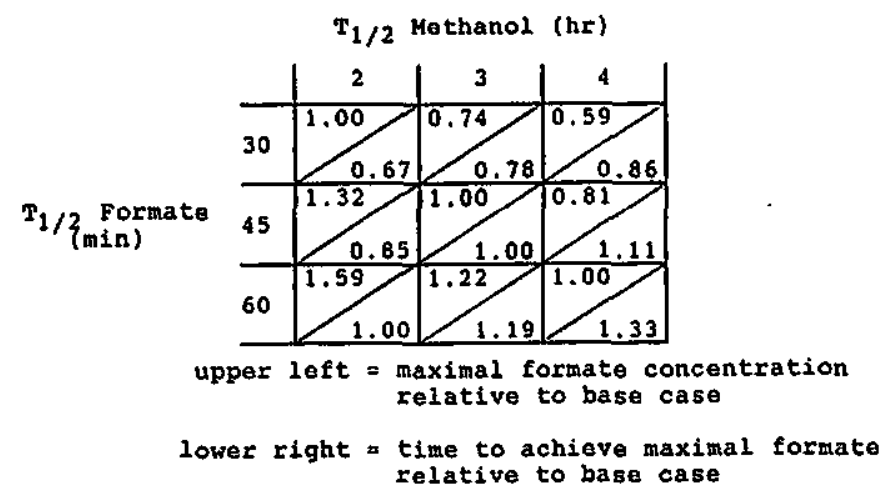

Note: In reference condition (middle cell), halftime for methanol clearance is $3 \mathrm{~h}$ and for formate it is $\mathbf{4 5} \mathrm{min}$. Upper left of each cell is relative blood formate level; lower right is relative time to achieve maximal concentration.

degree. In addition, formate peaks, for all cases shown, within 1.3 to $2.7 \mathrm{~h}$ of exposure. However, all the curve shapes remain similar to the one plotted for the example.

\section{REFERENCES}

1. Gold, M. D., Organic emission standards for light-duty methanotfueled vehicles: a methodology, presented at the 78th Annu. Meet. Air Pollut. Control Assoc., Detroit, MI, June 16 to 21, 1985.

2. Report of the Three-Agency Methanol Task Force. Vol. I. Executive Summary; Vol. II. Appendices, Air Resources Board, California Energy Comm. and South Coast Air Quality Management District, 1986.

3. Harvey, C. A., Carey, P. M., Somers, J. H., and Garbe, R. J., Toxicologically acceptable levels of methanol and formaldehyde emissions from methanol-fueled vehicles, SAE Technical Paper Series, \#841357, Fuels and Lubricants Meeting and Exposition, Baltimore, MD, 1984.

4. Gold, M. D. and Moulis, C. E., Effects of emission standards on methanol vehicle-related ozone, formaldehyde and methanol exposures, presented at the 81 st Annu. Meet. of the Air Pollut. Control Assoc., Detroit, MI, June 19 to 24, 1988.

5. Health Effects Institute, "Automotive Methanol Vapors and Human Health: an Evaluation of Existing Scientific Information and Issues for Future Research, a report of the Institute's Health Res. Comm. May, 1987.

6. Rowe, V. K. and McCollister, S. B., Alcohols, in Patry's Industrial Hygiene and Toxicology. Vol. 2C, 3rd ed., Clayton, G. D. and Clayton, F. E., Eds., John Wiley \& Sons, New York, 1982, 4528. 
7. Reed, T. B. and Lerner, R. M., Methanol: a versatile fuel for immediale use, Science, 182, 1299, 1973.

8. Posner, H. S., Biohazands of methanol in proposed new uses, $J$. Toxicol. Environ. Health, 1, 153, 1975.

9. Committee on the Institutional Means for Assessments of Risks to Public Health, Commission on Life Sciences National Research Council, Risk Assessment in the Federal Government: Managing the Process, National Academy Press, Washington, D.C., 1983.

10. Documentation of the Threshold Limir Values and Biological Exposure Indices, 5th ed., American Conference of Government Industrial Hygienists, Inc., Cincinnati, $\mathrm{OH}, 1985,372$.

11. Jelliffe, S. E., Multiple neuritis in wood alcohol poisoning, Med. News, 86, 387, 1905.

12. Wood, C. A., Death and blindness as a result of poisoning by methyl, or wood, alcohol and its varitous preparations, Int. Clin., 16, 68, 1906.

13. Chew, W. B., Berger, E. H., Brines, O. A., and Capron, M. J., Alkali treatment of methyl alcohol poisoning, JAMA, 130, 61, 1946.

14. Province, W. D., Kritzler, R. A., and Calhoun, F. P., Methy] alcohol poisoning. Report of cases, Bull. U.S. Army Med. Dept., 5, $114,1946$.

15. Bennett, I. L., Jr., Cary, F. H., Mitchell, G. L., Jr., and Cooper, M. N., Acute methyl alcohol poisoning: a review based on experiences in an outbreak of 323 cases, Medicine, 32, 431, 1953.

16. Kane, R. L., Talbert, W., Harlan, J., Sizemore, G., and Cataland, S., A methanol poisoning outbreak in Kentucky: a clinical epidemiologic study, Arch. Environ. Health, 17, 119, 1968.

17. Dethlefs, R. and Naraqi, S., Ocular manifestations and complications of acute methyl alcohol intoxication, Med. J. Aust., 2, 483, 1978.

18. Tyson, H. H. and Schoenberg, M. J., Experimental researches in methyl alcohol inhalation, JAMA, 63, 915, 1914.

19. Wood, C. A. and Buller, F., Poisoning by wood alcohol: cases of death and blindness from Columbian spirits and other methylated preparations, JAMA, 43, 972, 1904.

20. Buller, F. and Wood, C. A., Poisoning by wood atcohol: cases of death and blindness from Columbian spirits and other methylated preparations, JAMA, 43, 1058, 1117, 1213, 1289, 1904.

21. Wood, C. A., Death and blindness from methyl or wood-alcohol poisoning with means of prevention, JAMA, 59, 1962, 1912.

22. Ziegler, S. L., The ocular menace of wood alcohol poisoning, JAMA, $77,1160,1921$.

23. Litovitz, T. L., Acute exposure to methanol and fuels: a prediction of ingestion incidence and toxicity, Proc. Methanol Health Safety Workshop, sponsored by the South Coast Air Quality Management District, October 1988.

24. Gimenez, E. R., Vallejo, N. E., Roy, E., Lis, M., and Izurieta, E. M., Rossi, S., and Capuccio, M., Percutaneous alcohol intoxication, Clin. Toxicol., 1, 39, 1968.

25. Tyson, H. H., Amblyopja from inhalation of methyl alcohol, Arch. Ophthamol., 16, 459, 1912.

26. Roe, 0 ., The metabolism and toxicity of methanol, Pharmacol. Rev., 7. $399,1955$.

27. Tephly, T. R. and McMartin, K. E., Methanol metabolism and toxicity, in Aspartame: Physiology and Biochemistry. Stegink, L. D., and Filer, L. J., Jr., Eds., Marcel Dekker, New York, 1984, 111.

28. Jacobsen, D. and McMartin, K. E., Methanol and ethylene glycol poisonings. Mechanism of toxicity, clinical course, diagnosis and treatmene, Med. Toxicol., 1, 309, 1986.

29. Benton, C. D. and Calhoun, F. P., The ocular effects of methyl alcohol poisoning. Report of a catastrophe involving three hundred and twenty persons, Trans. Am. Acad. Ophthamol., 56, 875, 1952.
30. Casarett, L. J. and Doufl, J., Toxicology: The Basic Science Poisons, Casarett, L. J. and Doull, J., Eds., Macmillan, New Yos 1975.

31. Tonning, D. J., Methyl alcohol poisoning. A survey of thirty case Nova Scotia Med. Bull., 24, 1, 1945.

32. Kaplan, K., Methyl akcohol poisoning, Am. J. Med. Sci., 244, 170 1962.

33. Erlanson, P., Fritz, H., Hagstram, K. E., Llljenberg, B., Tryd Ing, N., and Voigt, G., Severe methanol intoxication, Acta Med Scand., 177, 393, 1965.

34. Aquilonius, S. M., Askmark, H., Enoksson, P., Lundberg P. O., and Mostrum, U., Computerised tomography in severe meth 3 ix anol intoxication, Br. Med. J., ii, 929, 1978.

35. Guggenheim, H. A., Couch, J. R., and Weinberg, W., Motos dysfunction as a permanent complication of methanol ingestion. Pres sentation of a case with a beneficjal response to levodopa treatment, Arch. Neural., 24, 550, 1971.

36. Ley, C. O. and Gali, F. G., Parkinsonian syndrome after methano Intoxication, Eur. Neurol., 22, 405, 1983.

37. Koivusalo, M., Methanol, in International Encyclopedia of Phar macology and Therapeutics, Section 20, Vol. 2, Tremolieres, J Ed., Pergamon Press, New York, 1970, 465.

38. Gonda, A., Gault, H., Churchill, D., and Hollomby, D. Hemodialysis for methanol intoxication, Am. J. Med., 64, 749 1978.

39. Becker, C. E., The alcoholic patient as a toxic emergency, Medit Clin. North Am., 2, 47, 1984.

40. De Schweinitz, G. E., A case of methyl-alcohol amaurosis, the pathway of entrance of the poison being the lungs and the cutaneous surface, Ophthal. Rec., 10, 289, 1901.

41. Hawes, A. T., Amblyopia from the fumes of wood alcohol, Boston Med. Sur. J., 153, 525, 1905.

42. Humperdinck, $\mathbf{K}$, On the problem of chronic intoxication with methanol vapors (in German), Arch. Gewerbepathol. Gerwerbehyg. 10, 569, 1941.

43. Burk, M., On chronic occupational methyl alcohol intoxication (i German), Klin. Montabl. Augenheilkd., 130, 845, 1957.

44. Greenburg, L., Mayers, M. R., Goldwater, L. J., and Burke W. J., Health hazards in the manufacture of "fused collars" II. Exposure to acetone-methanol, J. Ind. Hyg. Toxicol., 20, 148 1938.

45. Kingsley, W. H. and Hirsch, F. G., Toxicologic considerations in direct process spirit duplicating machines, Compens. Med., 40, 7 , 1954.

46. National Institute for Occupational Safety and Health, Health Hazard Evaluation Report, HETA 81-177, 178-188 (PB82-194648), 1981:

47. Frederick, L. J., Schulte, P. A., and Apol, A., Investigation and control of occupational hazards associated with the use of spirit do: plicators, Am. Ind. Hyg. Assoc. J., 45, 51, 1984.

48. Baumann, K. and Angerer, J., Occupational chronic exposure to organic solvents. VI. Formic acid concentration in blood and urint as an indicator of methanol exposure, Int. Arch. Occup. Environ Health, 42, 241, 1979.

49. Heinrich, R. and Angerer, J., Occupational chronic exposure ito organic solvents. $\mathrm{X}$. Biological monitoring paramesers for methanol exposure, Int. Arch. Occup. Environ. Health, 50, 341, 1982.

50. Chao, C.-T., Materials on the hygienic standardization of the max. imally permissible concentration of methanol vapors in the atmo? sphere (in Russian), Gig. Sanit., 24, 7, 1959.

51. Ubaydullayev, R., A study of hygienic properties of methanol as an atmospheric air pollutant, USSR Lit. Air Pollut. Relat. Occup Dis. - A Survey, 17, 39, 1963 (Levine, B. S., transl.).

52. Sedivec, V., Mraz, M., and Flek, J., Biological monitoring of 
persons exposed to methanol vapours, Int. Arch. Occup. Environ. Health, 48, 257, 1981.

53. Eriksen, S. P. and Kulkarni, A. B., Methanol in normal human breath, Scicnce, 141, 639, 1963.

54. Francot, P. and Geoltroy, P., Le methanol dans les jus de fruits, les boissons, fermentees, les alcools et spiriteux (in French), Rev. Ferment. Ind. Aliment., 11, 279, 1956.

55. Steglnk, L. D., Aspartame metabolism in humans: acute dosing studies, in Aspartame: Physiology and Biochemistry, Stegink, L. D. and Filer, L. J., Jr., Eds., Marcel Dekker, New York. 1984, 509.

56. Gagnon, C. and Heisler, S., Protein carboxyl-methylation: role in exocytosis and chemotaxis, Life Sci.. 25, 993, 1979.

57. Stegink, L. D., Brummel, M. C., Filer, L. J., Jr., and Baker, G. L., Blood methanol concentrations in one-year-old infants admintstered graded doses of aspartame, J. Nutr.. 113, 1600, 1983.

58. Stegink, L. D., Brummel, M. C., McMartin, K., Martin-Amat, G., Filer, L. J., Jr., Baker, G. L., and Tephly, T. R., Blood methanol concentrations in normal adult subjects administered abuse doses of aspartame, J. Taxicol. Environ. Health. 7, 281, 1981.

59. Evaluation of the Heahh Aspects of Formic Acid, Sodium Formate. and Eshyl Formate as Food Ingredients. Federation of American Societies for Experimental Biology, Prepared for Food and Drug Administration, Bureau of Foods, Washington, D.C., PB-266 282, 1976.

60. Report of the Federal Panel on Formaldehyde, Environ. Health Perspect., 43, 139, 1982.

61. Gllger, A. P. and Potts, A. M., Studies on the visual toxicity of methanol. V. The role of acidosis in experimental methanol poisoning, Am. J. Ophthalmol., 39, 63, 1955.

62. Gilger, A. P., Potts, A. M., and Johnson, L. V., Sudies on the visual toxicity of methanol. I1. The effect of parenterally administered substances on the systemic toxicity of methyl alcohol, Am. J. Ophthalmol., 35, 113, 1952.

63. Potts, A. M., The visual toxicity of methanol. VI. The clinical aspects of experimental methanol poisoning treated with base, Am. J. Ophthalmol., 39, 86, 1955.

64. Potts, A. M., Praglin, J., Farkas, I., Lowell, M. S., Orbison, L., and Chickerlng, D., Studies on the visual toxicity of methanol. VIII. Additional observations on methanol poisoning in the primate test object, Am. J. Ophtholmol., 40, 76, 1955.

65. Gilger, A. P., Potts, A. M., and Farkas, I. S., Studies on the visual toxicity of methanol. IX. The effect of ethanol on methanol poisoning in the rhesus monkey, Am. J. Ophthalmol., 42, 244, 1956.

66. Gilger, A. P., Farkas, I. S., and Potts, A. M., Sudies on the visual toxicity of methanol. X. Further observations on the ethanol therapy of acute methanol poisoning in monkeys, Am. J. Ophthalmol.. 48, 153, 1959.

67. Clay, K. L., Murphy, R. C., and Watkins, W. D., Experimental methanol toxicity in the primates: analysis of metabolic acidosis. Toxicol. Appl. Pharmacol., 34, 49, 1975.

68. MeMartin, K. E., Makar, A. B., Martin-Amat, G., Palese, M., and Tephly, T. R., Methanol poisoning. 1. The role of formic acid in the development of metabolic acidosis in the monkey and the reversal by 4-methylpyrazole, Biochem. Med., 13, 319. 1975.

69. White, L. R., Marthinsen, A. B. L., Richards, R. J., Elk-Nes, K. B., and Nilsen, O. G., Biochemical and cytological studics of rat lung after inhalation of methanol vapor, Toxicol. Lett., 17. I. 1983.

70. Andrews, L. S., Clary, J. J., Terrill, J. B., and Bolte, H. R., Subchronic inhalation toxicity of methanol, J. Toxicol. Environ. Health, 20, 117, 1987.

71. National Institute for Occupational Safety and Health, An Analysis and Critique of Behavioral Toxicology in the USSR, NIOSH-77-160. PB-273 807, 1976.

72. National Institute for Oceupational Safety and Health, Criteria for a Recommended Standard. Occupational Exposure to Methyl Alcohol. NIOSH-76-148, PB-273 806, 1976.

73. Cameron, A. M., Nilsen, O. G., Haug, E., and Etk-Nes, K. B., Circulating concentrations of testosterone, lutcinizing honmone and follicle stimulating hormone in male rats after inhalation of methanol, Arch. Toxicol. Suppl., 7, 411, 1984.

74. Cameron, A. M., Zahlsen, K., Haug, E., Nilsen, O. G., and EilkNes, K. B., Circulating steroids in male rats following inhalation of n-alcohols, Arch. Toxicol. Suppl., 8, 422, 1985.

75. Nelson, B. K., Brightuell, W. S., Mackenzte, D. R., Khan, A., Burg, J. R., Welgel, W. W., and Goad, P. T., Teratological assessment of methanol and ethanol at high inhalation levels in rats, Fundam. Appl. Toxicol., 5. 727, 1985.

76. Infurna $\mathbf{R}$. and Weiss B., Neonatal behavioral toxicity in rats following prenatal exposure to methanol, Teratology 33, 259, 1986.

77. Sayers, R. R., Yant, W. P., Schrenk, H. H., Chornyak, J., Pearce, S. J., Patty, F. A., and Linn, J. G., Methanol poisoning. II. Exposure of dogs for brief periods eight times daily to high concentrations of methanol vapor in air, J. Ind. Hyg. Toxicol., 26, 255. 1944.

78. Sayers, R. R., Yant, W. P., Schrenk, H. H., Chornyak, J., Pearce, S. J., Patty, F. A., and Linn, J. G., Methanol poisoning. I. Exposure of dogs to $450-500 \mathrm{ppm}$ methanol vapor in air, Report of Investigations RI 3617. U.S. Dept. of Interior, Bureau of Mines, 1942, 1.

79. Reynolds, W. A., Bauman, A. F., Stegink, L. D., Filer, L. J., Jr., and Naidu, S., Developmental assessment of infant Macaques receiving dietary aspartame or phenylalanine, in Asparıame: Physiology and Biochemistry. Stegink, L. D. and Filer, L. J., Jr., Eds., Marcel Dekker, New York, 1984, 405.

80. Suomi, S. J., Effects of aspartame on the leaming test performance of young Stumptail Macaques, in Aspariame: Physiology and Biochemistry, Stegink, L. D. and Filer, L. J., Jr., Eds., Marcel Dekker, New York, 1984, 425.

81. New Energy Development Organization. "Toxicological Research of Methanol as a Fuel for Power Station: Summary Report on Tests With Monkeys, Rats and Mice," October, 1987.

82. Takeda, K. and Katoh, M., Long-term effects of methanol vapor at low concentration, Proc. of the 8th Int. Symp. Alcohol Fuels, Tokyo, Japan, 1988.

83. Yant, W. P. and Schrenk, H. H., Distribution of methanol in dogs after inhalation and administration by stomach tube and subcutaneously, J. Ind. Hyg. Toxicol., 19, 337, 1937.

84. Leaf, G. and Zatman, L. J., A study of the conditions under which methanol may exert a toxic hazard in industry, Br. J. Ind. Med.. 9, 19. 1952.

85. Opperman, J. A., Aspartame metabolism in animals, in Aspartame: Physiology and Biochemistry, Stegink, L. D. and Filer, L. J., Jr., Eds., Marcel Dekker, New York, 1984, 141.

86. Eells, J. T., Black, K. A., Tedford, C. E., and Tephly, T. R., Methanol toxicity in the monkey: effects of nitrous oxide and methionine, J. Pharmacol. Exp. Ther., 227, 349, 1983.

87. Jacobsen, D., Ovrebo, S., Arnesen, E., and Paus, P. N., Pulmonary excretion of methanol in man, Scand. J. Clin. Lab. Invest., 43, 377, 1983.

88. Harger, R. N., Raney, B. B., Bridwell, E. G., and Kitchel, M. F., The partition ratio between air and water, urine and blood; estimation and identification of alcohol in these liquids from analysis of air equilibrated with them, J. Biol. Chem., 183. 197, 1950. 
89. Tephly, T. R., Parks, R. E., and Mannering, G. J., Methanol metabolism in the rat, J. Pharmacol. Exp. Ther.. 143, 292, 1964.

90. Makar, A. B., Tephly, T. R., and Mannering, G. J., Methanol netabolism in the monkey, Mol. Pharmacol., 4, 471, 1968.

91. Noker, P. E., Eells, J. T., and Tephly, T. R., Methanol toxicily: treatment with folic acid and 5-formyl tetrahydrofolic acid, Alco. holism: Clin. Exp. Res., 4, 378, 1980.

92. Makar, A. B. and Mannering, G. J., Role of the intracellular distribution of hepatic catalase in the peroxidative oxidation of methanol, Mol. Pharmacol., 4, 484, 1968.

93. Bartlett, G. R., Combustion of $\mathrm{C}^{14}$ Jabelled methanol in the intact rat and its isolated tissues, Am. J. Physiol., 163, 614, 1950.

94. Loomis, T. A., Essentials of Toxicology, Lea \& Febiger, Philadelphia, PA, 1968.

95. Klaasen, C. D., Amdur, M. O., and Doull, J., Eds., Casarent and Doull's Toxicology: The Basic Science of Poisons. MacMillan, New York, 1986.

96. Makar, A. B. and Tephly, T. R., Methanol poisoning. Vl. Role of folic acid in the productin of methanol poisoning in the rat, $J$. Toxicol. Environ. Healih, 2, 1201, 1977.

97. McMartin, K. E., Martin-Amat, G., Maker, A. B., and Tephly, T. R., Methanol poisoning: role of formate metabolism in the monkey, in Alcohol and Aldehyde Metabolizing Systems, Vol. 2, Thurman, R. G., Williamson, J. R., Drott, H., and Chance, B., Eds., Academic Press, New York, 1977, 429.

98. McMartin, K. E., Martin-Amat, G., Noker, P. E., and Tephly, T. R., Lack of role for formaldehyde in methanol poisoning in the monkey, Biochem. Pharmacol., 28, 645, 1979.

99. Malorny, G., Rietbrock, N., and Schneider, M., Die oxydation des formaldehyde zu ameisensaure in blut, ein beitrag zum stoffwechsel des formaldehyde (in German), Naunyn-Schmiedebergs Arch. Exp. Pathol. Pharmakol., 250, 419, 1965.

100. Rietbrock, N., Formaldehydroxydation bei der ratte (in German), Naunyn-Schmiedebergs Arch. Exp. Pathol. Pharmacol., 251, 189, 1965.

101. Martin-Amat, G., Tephly, T. R., McMartin, K. E., Makar, A. B., Hayreh, M. S., Hayreh, M. S., Baumbach, G., and Cancilla, P., Methyl alcohol poisoning. II. Development of a model for ocular toxicity in methyl alcohol poisoning using the Rhesus monkey, Arch. Ophthalmol., 95, 1847, 1977.

102. Malorny, G., Stoffwechselversuche mit natrium-formiat und ameisensaure beim menschen (Acute and chronic toxicity of formic acid and formates) (in German), Z. Ernaehrungswiss., 9, 332, 1969.

103. Rietbrock, N., Kinetic und wege des methanolumsatzes (Kinetics and pathways of methanol metabolism) (in German), Naunyn-Schmie. debergs Arch. Pharm. Exp. Parhol., 263, 88, 1969.

104. Maker, A. B. and Tephly, T. R., Methanol poisoning in the folatedeficient rat, Nouture, 261, 715, 1976.

105. Palese, M. and Tephy, T. R., Metabolism of formate in the rat, J. Toxicol. Environ. Health, 1, 13, 1975.

106. McMartin, K. E., Martin-Amat, G., Makar, A. B., and Tephly, T. R., Methanol poisoning. V. Role of formate metbolism in the monkey. J. Pharmacol. Exp. Ther., 201, 564, 1977.

107. Eeels, J. T., Makar, A. B., Noker, P. E., and Tephly, T. R., Methanol poisoning and formate oxidation in nitrous oxide treated rats, J. Pharmacol. Exp. Ther., 217, 57, 1981.

108. Eells, J. T., Black, K. A., Makar, A. B., Tedfod, C. E., and Tephly, T. R., The regulation of one-carbon oxidation in the rat by nitrous oxide and methionine, Arch. Biochem. Biophys., 219, 316, 1982.

109. Black, K. A., Eells, J. T., Noker, P. E., Hawtrey, C. A., and Tephly, T. R., Role of hepatic tetrahydrofolate in the species dif- ference in methanol toxicity, in Proc. Natl. Acad. Sci. U.S.A., 3854, 1985.

110. Johlin, F..C., Jr., Fortman, C. S., Nghiem, D. D., and Teph

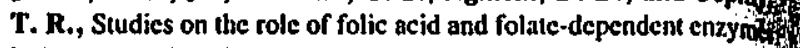
in human methanol poisoning, Mol. Pharmacol., 31, 557, 1987.

111. Tephly, T. R., Introduction: factors in responses to the environmeñ Fed. Proc., 36, 1627, 1977.

112. Hayreh, M. S., Hayreh, S. S., Baumbach, G. L., Cancllla, , $^{\circ}$ Martin-Amat, G., Tephly, T. R., McMartin, K. E., and Makat A. B., Methyl alcohol poisoning. 1II. Ocular toxicity, Arch. Ophtholy mol., 95, 1851, 1977.

113. Baumbach, G. L., Cancilta, P. A., Martin-Amat, G., Tephiy T. R., McMartin, K. E., Makar, A. B., Hayreh, M. S., and Hayreh, S. S., Methyl alcohol poisoning. IV. Alierations of the morphological findings of the retina and optic nerve, Arch. Ophthail mol., 95, 1859, 1977.

114. Nicholls, P., Formate as an inhibitor of cytochrome $c$ oxidase, Biochems Biophys. Res. Commun., 67, 610, 1975.

115. Nicholls, P., The effects of formate on cytochrome aa and on eleoth tron transport in the intact respiratory chain, Bioch. Biophys. Actajy 430, 13, 1976.

116. Martin-Amat, G., McMartin, K. E., Hayreh, S. S., Hayreh, M. S., and Tephly, T. R., Methanol poisoning: ocular toxicity produced by formate, Toxicol. Appl. Pharnacol., 45, 201, 1978,

117. Malorny, G., Metabolism studies with sodium formate and formich acid in man (in German), Z. Ernaehrungswiss.. 9, 340, 1969. 